\title{
EL DAÑO MORAL EN MATERIA CONTRACTUAL: LA MIRADA DE LA CORTE SUPREMA
}

\author{
NON-PECUNIARY DAMAGES IN CONTRACT: \\ THE VIEW OF THE SUPREME COURT
}

\begin{abstract}
IÑigo de la Maza GazMuri*
RESUMEN: Generalmente, la cuestión de la procedencia del daño moral en materia contractual es intensamente debatida. El problema ya no es si procede o no, sino, más bien, bajo qué condiciones debería proceder. Este trabajo intenta presentar y examinar críticamente un grupo de sentencias de la Corte Suprema dictadas entre los ańos 2005 y 2016 y proponer ciertos dispositivos para enfrentar lo que aquí se ha denominado una "respuesta liberal" por parte de la Corte.
\end{abstract}

Palabras clave: Daño moral, contrato, Corte Suprema, previsibilidad, riesgos

ABSTRACT: Non-pecuniary damages in contract law are anywhere a strongly debated issue. The problem is not anymore that these kinds of damages are forbidden but the conditions under which they should be available. This work intends to present and, to some extent, critically examine some decisions of the Supreme Court on this topic issued from 2005 to 2016 and proposes some devices to face what is called here a "liberal answer" of the Supreme Court.

Keywords: Non-pecuniary damages, contract, Supreme Court, foreseeability, risks.

\section{INTRODUCCIÓN}

Al menos sobre una cosa existe claridad, y es que la cuestión del daño moral en materia de contratos no resulta clara, ni en Chile, ni en ninguna parte ${ }^{1}$. La claridad comenzó a acabarse junto a la cerrada disciplina que negaba todo tipo de daño moral en materia contractual. Luego vinieron las sentencias que, preliminarmente y para ciertos contratos, aceptaron su procedencia. Finalmente, al menos en el ámbito chileno, la sentencia de 20 de octubre de 1994, por así decirlo, puso fin al ancien régime, pavimentando el camino hacia una amplia aceptación del daño moral por incumplimiento contractual ${ }^{2}$.

\footnotetext{
Abogado; Doctor en Derecho; Profesor Investigador Facultad de Derecho de la Universidad Diego Portales; Profesor de Derecho Civil; Dirección postal: República 105, Santiago de Chile. Dirección electrónica: inigo.delamaza@udp.cl. Este artículo se enmarca en el Proyecto Fondecyt regular no 1161380. Aprovecho aquí de agradecer la enorme ayuda que me han prestado mis ayudantes de investigación Vicente Martínez Valenzuela y Nicolás Montes Serrano por una ayuda extraordinariamente útil en este investigación. Todos los errores que puedan subsistir en este trabajo me resultan imputables.

Ver, por ejemplo, Palmer (2015), Kramer (2010) pp. 493-517, Díez-Picazo (2008), Goldberg (1986).

2 Rafael Mouthon, María con Banco de Chile (1994).
} 
Se ha transitado, entonces, desde una ordenada negativa hacia una recepción más bien indiscriminada del daño moral en materia contractual. Ninguno de los dos extremos aparece deseable. La disciplinada negativa frente a la indemnización del daño moral por incumplimiento contractual peca por defecto, la indiscriminada recepción peca por exceso. En otras palabras, negar siempre la indemnización por daño moral, obviaba el hecho que los contratos pueden dirigirse a la tutela de intereses extrapatrimoniales. Acoger indiscriminadamente el daño moral por incumplimiento contractual obvia el hecho de que no todo contrato se dirige a la tutela de intereses extrapatrimoniales.

Este trabajo constituye un intento de mostrar el estado de la cuestión en las sentencias de la Corte Suprema, a través del examen de una muestra de las sentencias de dicho Tribunal entre los años 2005 y 2016. Su objetivo es, de una parte, mostrar que, normativamente, la aceptación indiscriminada del daño moral frente al incumplimiento contractual es incorrecta. De otra, se trata de sugerir algunas formas de corregir el estado de las cosas.

Consideradas esas sentencias se aprende que, al menos en términos generales, actualmente, la Corte Suprema acepta en términos particularmente generosos la procedencia del daño moral en los incumplimientos contractuales. Y esto se explica, mayoritariamente, por dos razones. La primera de ellas es que la noción de daño moral que ha empleado la Corte resulta extraordinariamente amplia, llegando, en ocasiones, a cubrir las simples molestias o la angustia que suele provocar un incumplimiento contractual. La segunda razón que explica este resultado se encuentra en la justificación de la procedencia del daño moral que, generalmente, ha empleado la Corte. Se trata de una justificación que, conspicuamente, desatiende el rol limitador que puede tener el contrato respecto de la procedencia de daño moral por incumplimiento contractual.

Junto con esa aproximación predominante de la Corte a la cuestión del daño moral resulta posible detectar otra minoritaria en la cual presta atención tanto a la noción de daño moral como a lo que puede denominarse su "ámbito de resguardo". Lo que se sostiene en este trabajo es que parece adecuado, en primer lugar, matizar la amplitud de la noción de daño moral para excluir las simples molestias que, inevitablemente, genera un incumplimiento y, en segundo lugar, que el ámbito de resguardo del contrato presta utilidad para distinguir aquellos contratos que protegen intereses extrapatrimoniales de aquellos que no. Emplear esa noción mínimamente restringida del daño moral y el ámbito de resguardo del contrato puede contribuir significativamente a controlar la amplitud de la procedencia del daño moral frente al incumplimiento contractual.

\section{LAS ETAPAS DEL DAÑO MORAL Y LAS SENTENCIAS}

\subsection{Tres etapas en la Vida del daño moral EN SEDE CONTRACtual}

Con el inevitable riesgo de arbitrariedad que impregna esfuerzos de esta naturaleza, resulta posible identificar tres etapas en la posición que se ha asumido en el ámbito nacional respecto de la procedencia de indemnización por daño moral frente a un incumplimiento contractual por parte de los tribunales. 
La primera de estas etapas, que se extiende, aproximadamente, hasta mediados del siglo XX corresponde al rechazo de esta partida indemnizatoria justificada en que la patrimonialidad de los contratos la excluía ${ }^{3}$.

A partir de la década del 50, según reportan los autores, los tribunales comienzan a aceptar la indemnización respecto de ciertos contratos. Así, por ejemplo, de transporte ${ }^{4}$, trabajo ${ }^{5}$ o préstamo de dinero ${ }^{6}$. Existe así una segunda etapa.

Como se ve, entonces, lo que separa esta etapa de la previa es que se abandona el rechazo irrestricto de la anterior. Lo que, en cambio, la diferencia de la posterior es que no existe todavía en ella (en la segunda) una argumentación que, en términos generales -es decir, no limitada a uno o más tipos contractuales- acepte la indemnización del daño moral en materia contractual.

Esto último parece ser distintivo de la tercera etapa y resulta claro en la sentencia que, probablemente, la inaugura, la sentencia de la Corte Suprema de 20 de octubre de 19947. Es en este fallo donde -hasta donde llegan mis noticias- por primera vez la Corte Suprema se hace cargo de manera sistemática de un conjunto de argumentos que justifican de manera amplia -no limitada a determinados contratos- la procedencia de la indemnización del daño moral por incumplimiento contractual. En palabras de la profesora Carmen Domínguez ${ }^{8}$ esa sentencia se transforma en jurisprudencia a partir de otra de la Corte Suprema, esta vez, de 5 de noviembre de $2001^{9}$.

Más adelante volveré sobre esos argumentos y la forma en que la Corte los ha seguido empleando en sus sentencias posteriores. Lo que me interesa enfatizar ahora es que esos argumentos admiten ampliamente la indemnización por daño moral en sede contractual.

\subsection{AproXimaciones CONSERVAdoras y liberales Frente AL DAÑo MORAL}

Una sentencia de la Corte Suprema de 16 de mayo de 2012 sobre daño moral derivado del incumplimiento de un contrato que obligaba a mantener la ruta en óptimas condiciones ${ }^{10}$, señala lo siguiente: "Que es conocido como, desde antaño, se discutía la procedencia de la compensación del daño moral en sede del estatuto de la responsabilidad contractual. Sin embargo, también es una idea extendida ya, que aquel debate se ha visto mayoritariamente superado, desde luego lo ha sido por esta Corte Suprema, por amplios sectores de la doctrina y por la generalidad de la jurisprudencia. De allí, entonces, cabe

\footnotetext{
3 En este sentido Jana y Tapia (2004) p. 176, señalan que: "hasta el año 1950 existió una posición jurisprudencial unánimemente hostil a la indemnización de estos perjuicios en sede contractual, fundada en que la patrimonialidad de los contratos excluía tal posibilidad." Sobre el argumento de la patrimonialidad puede consultarse Domínguez (2000) pp. 170-227.

Ver Jana y TAPIa (2004) p. 178

Ver Jana y Tapia (2004) p. 178.

Ver Domínguez (2000) pp. 351-352.

Rafael Mouthon, María con BANCo de Chile (1994).

Domínguez (2006) p. 231.

Hugo Ruiz Ruiz; con Laboratorio Biológico SA Y otros (2001).

10 Ramírez y otro con Ruta de los Ríos Sociedad Concesionaria S.A. (2011).
} 
afirmar que el daño moral en el citado régimen ha de entenderse como un principio general del sistema de responsabilidad civil de nuestro país" ${ }^{\prime 1}$.

¿Qué quiere decir, exactamente, que en materia contractual el daño moral (habrá que entender la indemnización del daño moral) "ha de extenderse como un principio general de responsabilidad civil de nuestro país?”.

Una respuesta posible es que quiere decir que, a diferencia de lo que sucedía antes de 1994 no existe una justificación a priori para rechazar generalmente la indemnización del daño moral en materia contractual. Pero esta respuesta que, a estas alturas parece trivialmente obvia, exige cuestionarse algo más. Del hecho que no deba afirmarse que el daño moral no procede frente a incumplimientos contractuales no se sigue que proceda siempre. Se sigue, más bien, que es necesario determinar bajo qué condiciones procede.

Y, en esta tarea es posible, utilizando la terminología de Palmer, distinguir aproximaciones más "liberales" y otras más "conservadoras" frente a la procedencia del daño moral en supuestos de incumplimiento contractual ${ }^{12}$. Una aproximación resultará más liberal o más conservadora, según la intensidad de los requisitos que se exijan para conceder esta partida indemnizatoria.

Este trabajo considera que, por lo general, la recepción del daño moral por incumplimiento contractual de la Corte Suprema ha sido, mayoritariamente al menos, liberal, en el siguiente sentido. Con frecuencia, cuando la Corte reflexiona a propósito del daño moral se pregunta acerca del incumplimiento y la causación de un daño. En primer lugar, define el daño moral de una manera extraordinariamente amplia. En segundo lugar, no suele prestar atención a la forma en que el mismo contrato limita la procedencia del daño moral. En estos términos, su aproximación es liberal, pues las condiciones de procedencia de la indemnización por daño moral parecen particularmente modestas.

De manera más excepcional, resulta posible identificar una aproximación más conservadora en las sentencias de la Corte. $\mathrm{Y}$ es más conservadora pues somete al daño moral a un test de procedencia más estricto. El mayor rigor de este test queda determinado porque la noción de daño moral es menos amplia y porque se considera la forma en que el mismo contrato puede limitar la procedencia del daño moral.

\subsection{LAS SENTENCIAS}

Calibraré estas dos aproximaciones echando mano a una serie de sentencias de la Corte Suprema, dictadas entre el 27 de julio de 2005 y el 3 de mayo de $2016^{13}$. Ahora bien, conviene advertir que considerar únicamente las sentencias de la Corte Suprema presenta ciertas limitaciones. Ante todo, que no resulta infrecuente que las sentencias de la Corte Suprema se limiten a indicar, en una página o algo más, que los jueces de fondo han tenido por establecido el daño moral y que no se ha denunciado infracción a leyes re-

\footnotetext{
11 Ramírez y otro con Ruta de los Ríos Sociedad Concesionaria S.A. (2011). Considerando 17. El mismo párrafo se encuentra en la sentencia de CANET CON COLEGIO SALESIANO VALPARAÍSO (2009) sobre incumplimiento de un contrato de educación por parte del Colegio Salesianos de Valparaíso.

12 Palmer (2015) pp. 95-110.

13 Y aquí aprovecho de agradecer, una vez más, la enorme e inteligente ayuda del Juez José Luis Maureira.
} 
guladoras de la prueba ${ }^{14}$ o bien que el recurso de casación pretende desvirtuar los supuestos fácticos asentados en los autos ${ }^{15}$ o bien que se omitió extender la infracción legal a las normas que tienen el carácter de decisoria de la litis ${ }^{16} \mathrm{y}$, por lo mismo, sin más, se desecha. Probablemente, una segunda limitación es que no necesariamente se encuentra recogida de forma adecuada la discusión de las partes y eso impide saber si se discutió -y con qué argumentos- la cuestión de la limitación por daño moral.

Se trata de 149 sentencias. En 114 de ellas se acogió la indemnización del daño moral. Por lo tanto, en 35 se negó. De estas últimas, en 14 la negativa fue por falta de prueba.

A continuación, entre los contratos por cuyo incumplimiento se solicita la indemnización por daño moral es posible encontrar compraventas, promesas, arrendamientos, cuentas corrientes, mutuos, depósitos, hipotecas, mandatos, contratos que involucran prestaciones médicas (generalmente, intervenciones quirúrgicas y diagnósticos, transporte de personas y mercadería, contratos con previsión médica, construcción de obra material, seguros, servicios jurídicos, servicios educacionales y transacción, entre otros.

Por otra parte, los montos de las indemnizaciones fluctúan entre $\$ 150.000 .000^{17} \mathrm{y}$ $500.000^{18}$. Las sumas más altas parecen concentrarse en contratos de prestaciones médicas, así por ejemplo, además del caso de los $\$ 150.000 .000$, se han concedido $\$ 30.000 .000$ por unos implantes mamarios realizados incorrectamente ${ }^{19}, \$ 80.000 .000$ por una electromiografía realizada defectuosamente ${ }^{20}, \$ 72.000 .000$ el médico y $\$ 42.000 .000$ el hospital por la muerte de un feto ${ }^{21}$ y $\$ 40.000 .000$ por una histerectomía ${ }^{22}$. Sin embargo, también es posible encontrar, aunque de manera más dispersa, sumas nada despreciables en otros contratos. Así, por ejemplo, $\$ 25.000 .000$ por incumplimiento de un contrato de tarjeta de crédito $^{23}, \$ 12.000 .000$ por unos contratos de edición ${ }^{24}, \$ 12.000 .000$ por un contrato de venta de inmueble ${ }^{25}$, o $\$ 10.000 .000$ por un contrato de arrendamiento de local comercial $^{26}$.

En fin, todo indica que existe un marcado aumento en el número de demandas por incumplimiento contractual que solicita la indemnización por daño moral. De esta manera, en la muestra con que se ha trabajado aquí, a partir del 26 de julio de 2005 existe una

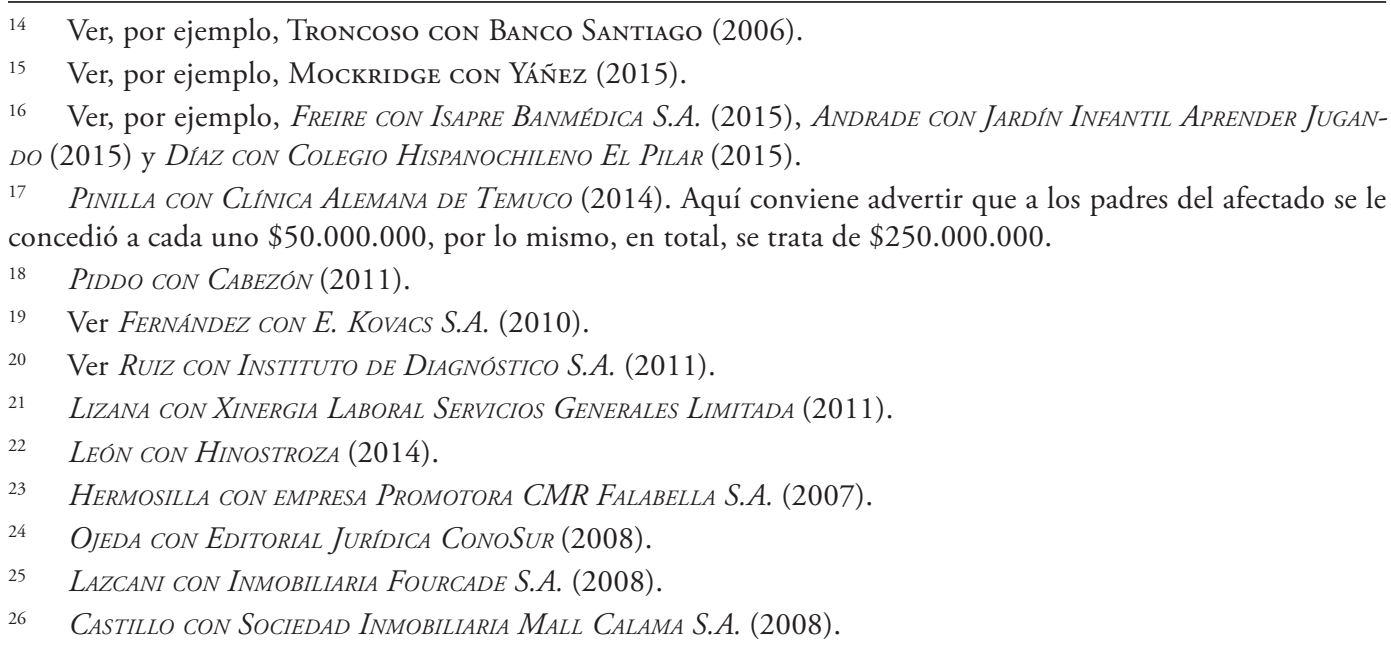


sola sentencia para ese año. 2 durante el 2006, 4 durante el 2007, 8 durante el 2008, 10 durante el 2009, 11 durante el 2010 y, en fin, para no hacer innecesariamente fatigosas las cosas, 34 durante el año 2015.

\section{LA APROXIMACIÓN LIBERAL A LA PROCEDENCIA DEL DAÑO MORAL POR INCUMPLIMIENTO CONTRACTUAL}

He denominado la "aproximación liberal" a la pregunta acerca de la procedencia de la indemnización por daño moral en sede contractual a aquella que, en primer lugar, no presta atención al ámbito de resguardo del contrato y, en segundo lugar, emplea una noción extraordinariamente amplia de daño moral.

Un par de ejemplos deberían resultar de utilidad para ilustrar el punto. El primero de ellos corresponde a una sentencia de 23 de junio de $2011^{27}$ y, el segundo, a una sentencia de 26 de marzo de $2012^{28}$.

En la primera de ellas, se trata de incumplimiento de un contrato de transporte de mercaderías celebrado entre dos personas jurídicas con fines de lucro. En lo que aquí interesa, la Corte condenó a la parte incumplidora al pago de una indemnización de $\$ 1.000 .000$ por concepto de daño moral. El argumento de la Corte respecto del daño moral fue el siguiente: "Que en relación a esta última causal de nulidad de fondo, tanto el artículo 1489, como el 1556 y 1557, todos del Código Civil, más bien sustentan la hipótesis jurídica del fallo del tribunal ad quem, en cuanto tanto a la acción resolutoria, como la norma sobre la reparación de perjuicios surgidas después de la promulgación del Código Civil, provenientes del incumplimiento de obligaciones contractuales llevaron a que el resarcimiento del daño moral derivado del incumplimiento de contratos se imponen en el derecho actual y la aceptación de dichas tendencias en la jurisprudencia de nuestros tribunales han determinado que el concepto de daño (sic.) emergente que emplea la norma del artículo 1556 del Código Civil, comprende no solamente el daño pecuniario sino también el extrapatrimonial o moral, interpretación que no solo es posible, sino que plenamente aceptable en (sic.) el texto actual del mencionado artículo, primero porque la voz "daño" que emplea la disposición y que no se encuentra definida en la ley corresponde según el Diccionario de la Real Academia de la Lengua Española a todo "detrimento, perjuicio, menoscabo, dolor o molestia"; es decir, a toda privación de bienes materiales e inmateriales o morales y, porque como antes quedó consignado, lo preceptuado en el citado artículo no excluye la consideración de otros perjuicios que no sean solo los materiales" 29 .

En la segunda sentencia se trata de la venta de 1.000 sacos de semillas de papa. La parte demandada entregó semillas de una variedad diversa a la convenida. Por lo que toca al daño moral, la Corte se limita a afirmar lo siguiente: "Que, por último, se apreciará prudencialmente el daño moral sufrido por el actor, entendido como una lesión a sus

\footnotetext{
Kreuzer Pacheco Hermanos Ltda. con Ronald Chaytor y Cia. Ltda. (2011).

Ramírez, José SANTIAGo CON KLEIN BRINTRUP, EdUARDo Augusto (2012).

Kreuzer Pacheco Hermanos Ltda. con Ronald Chaytor y Cia. Ltda. (2011). Considerando 12.
} 
intereses extrapatrimoniales ocasionada por el actuar negligente de la parte demandada, graduándolo en la suma de $\$ 5.000 .000$ (cinco millones de pesos)"30.

Pues bien, lo peculiar es que en ambas sentencias se trata de contratos con un marcado contenido patrimonial, sin embargo, la Corte ni siquiera considera el contrato para evaluar la procedencia del daño moral. Por otra parte, en la primera de las sentencias se trata de personas jurídicas, por lo tanto, la noción de daño moral que, implícitamente, acoge la Corte resulta suficientemente amplia como para comprenderlas. En la segunda sentencia parece ser que daño moral equivale, sencillamente, a lesión de intereses extrapatrimoniales, sin mayor cualificación.

La tesis que intentaré defender en este trabajo es que la respuesta inflacionaria se explica por dos razones. La primera de ellas es la enorme amplitud de la noción de daño moral que ha empleado, generalmente la Corte Suprema. En conjunto con lo anterior, se explica porque en la justificación de la procedencia del daño moral, la Corte no suele considerar el contrato en la limitación de la procedencia de dicha partida indemnizatoria.

Resultará útil explorar ambas cuestiones por separado.

\subsection{LA NOCIÓN DE DAÑO MORAL}

Con respecto a la noción de daño moral, convendrá comenzar advirtiendo que, en general, existe bastante acuerdo, en que se trata de una noción negativa. Así, por ejemplo, Zimmermann ha señalado que: "The only universal if trivial truth is that non-pecuniary damage is all damage that is not of a pecuniary nature... [I]t appears to be very difficult, if not impossible, to define the concept positively" ${ }^{\text {"1 }}$.

Sin embargo, no es este carácter negativo lo que llama la atención en las sentencias de los tribunales chilenos. Para entender qué es lo que interesa aquí se puede continuar advirtiendo que, como ha señalado Carrasco Perera, el daño moral se puede concebir de dos maneras, la primera es objetiva en términos que los intereses de carácter patrimonial que pueden ser lesionados son limitado ${ }^{32}$. En cambio, en la versión subjetiva, quedaría comprendido cualquier interés jurídico de carácter extrapatrimonial. De esta manera, derechos como el francés o el español optan por una concepción subjetiva; el alemán, en cambio, por una objetiva ${ }^{33}$. ¿Qué sucede en el ámbito nacional? Algunas sentencias contribuirán a mostrar la respuesta.

En una sentencia de 26 de octubre de 2015 sobre responsabilidad del propietario primer vendedor, la Corte Suprema, define al daño moral en los siguientes términos: "El daño moral se define como el sufrimiento, trastorno sicológico, afección espiritual o lesión de un interés personalísimo, ocasionado a la espiritualidad del ofendido, como consecuencia de la comisión de un hecho ilícito o de la vulneración de un derecho subjetivo, no definible por parámetros objetivos, susceptible de afligir a la víctima o a un tercero, y que

Ramírez, José Santiago con Klein Brintrup, Eduardo Augusto (2012). Considerando 7.

Tomo la cita de Palmer (2015) p. 5. Una crítica a esta noción en Domínguez Hidalgo (2000) pp. 54-55.

Carrasco (2010) pp. 1230-1231.

Ver Palmer (2015) pp. 96-106. 
puede traducirse en un daño moral puro o bien de índole pecuniario, cuando indirectamente menoscaba la capacidad productiva del perjudicado" 34 .

Por otra parte, la Corte ha explicitado que no es posible acudir a parámetros objetivos. En este sentido puede considerarse la sentencia de la Corte Suprema de 30 de marzo de 2012 respecto de un contrato de cuenta corriente en el que el Banco pagó un cheque con firma disconforme ${ }^{35}$ y en cuyo considerando duodécimo se lee lo siguiente: "Que entendido el daño moral como el sufrimiento, trastorno sicológico, afección espiritual o lesión de un interés personalísimo, causado a la espiritualidad de la víctima como consecuencia de la comisión de un hecho ilícito o de la infracción a un derecho subjetivo, no definible por parámetros objetivos, que puede afectar a la víctima o a un tercero..."36.

En un sentido semejante, en una sentencia de 12 de agosto de 2015, la Corte Suprema se ha referido a "la índole netamente subjetiva que tiene el daño moral y que encuentra su fundamento en la naturaleza afectiva del ser humano" ${ }^{37}$.

El punto, entonces, es claro: consistentemente la Corte Suprema ha concebido el daño moral de manera subjetiva y, podría agregarse, muy amplia. Así, por ejemplo, en la sentencia de la Corte Suprema de 2 de octubre de 2013 sobre incumplimiento de contrato de avenimiento se lee lo siguiente: "Es así como se ha entendido el daño moral como el pesar, dolor o molestia que sufre una persona en su sensibilidad física o en sus sentimientos, creencias o afectos. Si atendemos al concepto, este abarca no solo las lesiones a bienes de la personalidad, lo que en estricto rigor constituye daño moral, sino que además quedan comprendidos las lesiones corporales, la aflicción psicológica y la pérdida de oportunidades para disfrutar de la vida.

De esta manera y considerando la lesión de un interés jurídicamente relevante, se puede llegar a la compensación del daño no patrimonial no solo por el dolor o sufrimiento que se padece. Sobre esto, la visión reduccionista del daño moral pertenece al pasado, por lo que el daño extrapatrimonial protege más allá incluso del pretium doloris, que es solo una especie del mismo. Así, si la víctima ha sufrido un daño corporal (biológicofisiológico y estético) o un daño a la dignidad humana o a otros derechos de la personalidad, debe ser indemnizada por daño moral ${ }^{38}$. En esta misma línea, la profesora Carmen Domínguez Hidalgo, explica que la definición de daño moral debe ser lo más amplia posible, incluyendo todo daño a la persona en sí misma (física-psíquica), como todo atentado contra sus intereses extrapatrimoniales, esto es como todo menoscabo en un bien no patrimonial o a un interés moral por quien se encontraba obligado a respetarlo, ya sea en virtud de un contrato o de otra fuente" 3 .

\footnotetext{
TRUJILlO CON MUNDI Y OTROS (2015). Considerando 30

OLIVI, GERMÁN CON BANCO SANTANDER CHILE (2011).

Olivi, Germán con Banco Santander Chile (2011). Considerando 12.

Quiero CON SOCIEDAD DE TURISMO CONCEPCIÓN (2015).

BARRIENTOS (2008) pp. 85-106.

Stange, EduARDo CON Ripley Puerto MontT (2012). Considerando 28.
} 
A lo dicho, habrá que añadir que, como se ha visto, la Corte Suprema ha conceptualizado el daño moral de una manera que no solo alcanza a las personas naturales, sino que también a las jurídicas ${ }^{40}$.

Conceptualizado el daño moral de esta manera extraordinariamente amplia, no ha de extrañar que alcance incluso a las simples angustias o aflicciones que, de manera más bien necesaria, genera un incumplimiento contractual. En este sentido, puede consultarse la sentencia de la Corte Suprema de 19 de enero de 2011, que concede la suma de $\$ 4.000 .000$ por concepto de indemnización por daño moral frente al incumplimiento contractual consistente en haber hecho un mal estudio de títulos ${ }^{41}$. Se señala en la sentencia que: “...se comparte el razonamiento duodécimo, en virtud del cual el tribunal de primer grado tiene por acreditado el daño moral sufrido por el demandante consistente en las angustias o aflicciones que padeció producto del incumplimiento de la demandada” ${ }^{\sharp 2}$.

Otra sentencia de la Corte Suprema, esta vez de 14 de agosto de $2012^{43}$, que resolvió el incumplimiento de un contrato de compraventa de vehículo motorizado condena a la demandada al pago de $\$ 1.000 .000$, señalando que este correspondería a: "las molestias e incomodidades generadas por el incumplimiento de la demandada y por el hecho de no ver cumplidas sus expectativas." Razonamientos semejantes pueden encontrarse a nivel de las sentencias de Corte de Apelaciones ${ }^{44}$.

A estas alturas, el punto debería quedar suficientemente demostrado: la Corte, consistentemente, ha utilizado una noción de daño moral de carácter subjetivo, con una amplitud tal que, de una parte, llega a cubrir a personas jurídicas y, de otra, en ocasiones al menos, considera las simples molestias que ha generado el incumplimiento contractual.

\subsection{La JUSTIFICACIÓN DE LA PROCEDENCIA DE DAÑo MORAL POR INCUMPLIMIENTO CONTRACTUAL}

Una mirada a las sentencias de la Corte Suprema muestra que resulta frecuente que la reflexión se enderece, por así decirlo, binariamente. Como si la discusión fuera si procede o no el daño moral, y no, en cambio, bajo qué condiciones procede.

Para advertir esta cuestión parece necesario prestar atención a la forma en que la Corte Suprema argumenta acerca de la procedencia del daño moral en sede contractual. Si

\footnotetext{
40 Pesquera Luis Andrade S.A. con Marine Harvest Chile S.A. (2008).

41 Escobar con Cooperativa de Ahorro y Crédito SAN Felipe Limitada (2011).

42 Escobar con Cooperativa de Ahorro y CRÉdto SAN Felipe Limitada (2011). Considerando 9.

43 Reyes, PATriCio CON Autofrance LTDA. (2012).

44 Así, por ejemplo, la sentencia CRUZ, MABEL CON BANCO SANTANDER CHILE (2013) sobre incumplimiento de contrato de cuenta corriente, consistente en no haberla cerrado cuando el cliente se lo indicó. En lo que aquí importa, la Corte estimó que el dańo moral: "es todo menoscabo o detrimento no patrimonial que afecta la integridad psíquica del individuo, como la alteración en la tranquilidad de espíritu, molestias personales, inversión de tiempo en la solución de un problema, no cumpliendo de expectativas ofrecidas, impotencia, frustración o enojo a causa de un mal servicio". Y condenó al Banco a pagar la suma de $\$ 500.000$ por este concepto. La misma Corte ha empleado ese concepto de daño moral en otras dos sentencias referentes a contratos disciplinados por la ley 19.496 sobre protección de los derechos de los consumidores, la primera de ellas de 14 de junio de 2013 CAR S.A. CON SAEZ ZAMBRANO JULIA (2013) y la segunda de 24 del mismo mes y año. SANDOVAL VASQUEZ Jorge ANDRÉs CON Distribuidora DE INDUSTRIAS NACIONALES S.A. (2013).
} 
bien no existe una sola forma de argumentar, existe una que, de una parte, es extremadamente detallada y, de otra, particularmente persistente.

Se trata de una argumentación cuyos orígenes pueden rastrearse en la sentencia de la Corte Suprema de 20 de octubre de 1994. En la muestra de sentencias que ha considerado este trabajo aparece -aunque con mucho mayor desarrollo- por primera vez en una sentencia de 24 de septiembre de 2007 sobre incumplimiento de un contrato de prestaciones médicas ${ }^{45}$.

Antes de considerar estos argumentos, convendrá acreditar que, como ya ha quedado dicho, son invocados con frecuencia por la Corte Suprema. De esta manera, los volvemos a encontrar en las sentencias de 15 de enero de 2008 sobre un contrato editorial ${ }^{46}$, de 27 de marzo de 2008 sobre incumplimiento de un contrato de compraventa de inmueble $^{47}$ de 25 de septiembre de 2008 sobre incumplimiento de contrato de construcción ${ }^{48}$, de 29 de octubre de 2008 sobre incumplimiento de contrato de compraventa ${ }^{49}$, de 7 de enero de 2009 sobre contrato de depósito ${ }^{50}$, de 26 de enero de 2009 sobre incumplimiento de contrato de ejecución de obra material ${ }^{51}$, de 7 de septiembre de 2010 sobre contrato de educación ${ }^{52}$, de 21 de octubre de 2010 sobre contrato de cuenta corriente ${ }^{53}$, de 11 de abril de 2011 sobre incumplimiento de contrato de depósito ${ }^{54}$, de 25 de julio de 2011 sobre incumplimiento de contrato de prestaciones médicas ${ }^{55}$, de 20 de octubre de 2011 sobre incumplimiento de contrato de ejecución de obra material ${ }^{56}$, de 13 de junio de 2012 sobre incumplimiento de contrato de práctica educacional ${ }^{57}$, y de 2 de octubre de 2013 sobre incumplimiento de contrato de transacción ${ }^{58}$.

Junto con estas sentencias, en las que los argumentos se ocupan prácticamente de manera literal, existen otras múltiples sentencias en las que se ocupan uno o más de estos argumentos. Así, por ejemplo, la sentencia de 11 de abril de 2007 sobre el incumplimiento de un mandato judicial se refiere al artículo 1556 y a la doctrina y sentencias de tribunales superiores ${ }^{59}$, la de 2 de septiembre de 2008 sobre incumplimiento de contrato de arrendamiento señala que el artículo 1558 no excluye el daño moral ${ }^{60}$, la de 5 de octubre de 2009 sobre incumplimiento compraventa de vehículo motorizado señala que el artículo

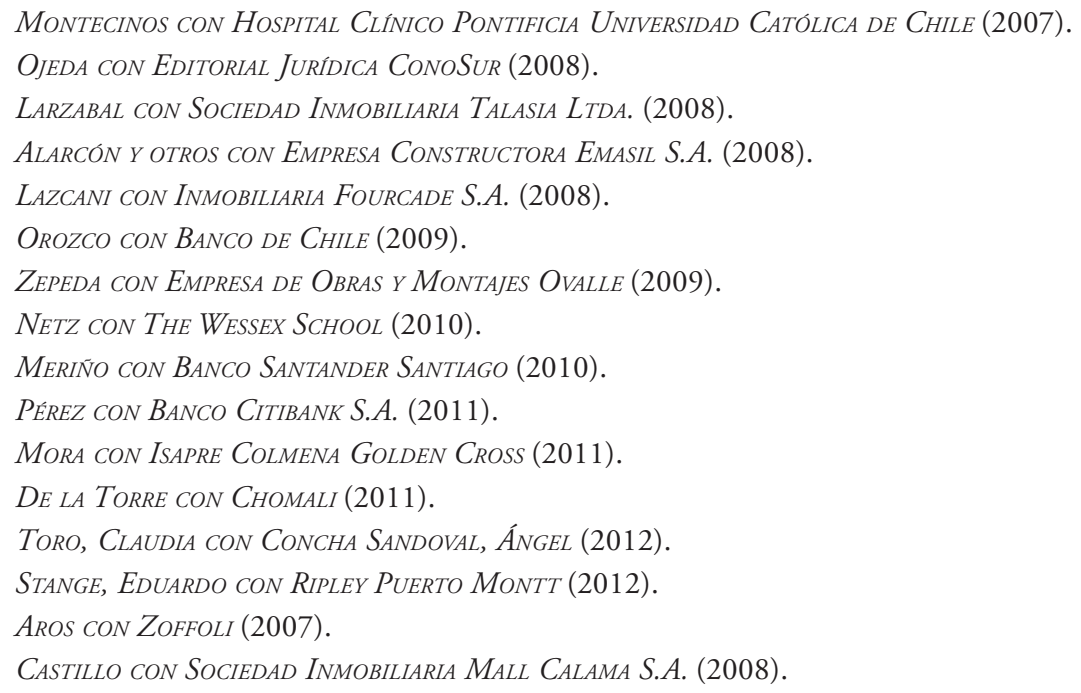


2314 no excluye el daño moral ${ }^{61}$, la de 19 de octubre de 2010 , sobre incumplimiento de un contrato de servicios se refiere a algunos fallos de la Corte Suprema y a la doctrina de las autores ${ }^{62}$, la de 23 de junio de 2011 sobre un contrato de prestaciones médicas indica que el artículo 1556 no excluye el daño moral ${ }^{63}$, la de 28 de septiembre de 2011 sobre vicios redhibitorios se refiere a la "visión integral del derecho" 64 y la de 10 de noviembre de 2014 sobre incumplimiento de promesa de inmueble que se refiere al artículo 1556, a la doctrina y a la jurisprudencia en términos semejantes ${ }^{65}$.

Pues bien, la extensión de los considerandos de la sentencia de 24 de septiembre de $2007^{66}$ impide su transcripción, sin embargo convendrá ahora identificar cuáles son los argumentos que desarrolla dicho fallo: (1) el artículo 1556 no debe interpretarse literalmente; (2) los tribunales han aceptado el daño moral desde 1994; (3) el legislador acepta el daño moral, el artículo 1556 no lo excluye; (4) el daño moral quedaría comprendido por el daño emergente a que se refiere el artículo 1556; (5) la doctrina ha aceptado la indemnización del daño moral en sede contractual (6) la igualdad ante la ley exige que se repare el daño moral en materia contractual. Junto a estos argumentos, la Corte se refiere, de manera muy confusa a una supuesta distinción entre procedencia y previsibilidad y otra, no menos confusa, entre daño moral puro y con repercusiones patrimoniales. Se añade, a continuación, un argumento de carácter constitucional, al abrigo de los artículos 19 No 7 letra i) y 19 No 24 , además de la idea de supremacía constitucional y aplicación directa de la Constitución. Luego, la Corte se refiere a la "teoría de la unidad de la responsabilidad" que justificaría que el daño moral únicamente se excluyera de la responsabilidad contractual cuando la ley exija culpa leve o levísima.

Más allá de los seis primeros argumentos, la argumentación de la Corte resulta extremadamente confusa y más bien carente de ilación, sin embargo, resulta necesario algún esfuerzo de sistematización. En primer lugar, existen un par de argumentos que podrían denominarse "de autoridad" (la Corte y la doctrina lo han aceptado antes). En segundo lugar, existen argumentos de carácter literal (el artículo 1556 no excluye el daño moral y este podría quedar cubierto por la expresión "daño emergente" que utiliza el precepto. En tercer lugar, hay argumentos que, de alguna manera se refieren a la fisonomía y función de la responsabilidad civil (la "unidad" de la responsabilidad civil y alguna idea relativa a la "reparación integral de los perjuicios" que procura anclarse en el texto constitucional respecto a la igualdad ante la ley).

Lo que, sin embargo, no hay son argumentos respecto al contrato como un dispositivo que asigna los riesgos del incumplimiento y que, eventualmente, limita la procedencia del daño moral. La Corte únicamente se refiere, de manera más bien confusa, a la previsibilidad, indicando que no debe confundirse con la procedencia del daño moral.

OLGUIN CON SOCIEDAd DE INVERSIONES Automotrices S. A. (2009).

MORIN CON CHILQUINTA ENERGIA S.A. (2010).

Kreuzer Pacheco Hermanos ltda. con Ronald Chaytor y Cia. Ltda. (2011).

Valenzuela y otros con InMobiliaria Petrohue S.A. y otra (2011).

Ochoran, EMilio con González Rojo, PABlo (2014).

Montecinos con Hospital Clínico Pontificia Universidad Católica de Chile (2007). 
De esta manera, la Corte no se ocupa de la relación entre previsibilidad y procedencia del daño moral en el sentido que la primera podría limitar la segunda.

Pues bien, la cuestión es, entonces, que en sus esfuerzos argumentativos más cuidadosos acerca del daño moral en materia contractual, la Corte parece haber obviado la forma en que el contrato puede limitar la procedencia de la indemnización por daño moral.

\subsection{El Reino de los matices ${ }^{67}$}

Una noción extraordinariamente amplia de daño moral unida a una justificación de su procedencia que desatiende el ámbito de resguardo del contrato arriesga una respuesta demasiado amplia respecto de la procedencia de la indemnización del daño moral en sede contractual.

Un resultado como este no debería resultar preocupante si los contratos se limitaran a aquellos que, indudablemente, comprometen intereses extrapatrimoniales como, generalmente, sucede con los de servicios médicos. Así, por ejemplo, llamaría profundamente la atención que, si se encuentra probado, no se concediera indemnización por daño moral en el caso en que, por falta de cuidado en el parto e inmediatamente después de este, un recién nacido quedó con secuelas e incapacidad física y síquica por toda la vida ${ }^{68}$. Si el contrato de prestación de servicios médicos por un parto no incorpora, de manera absolutamente predominante, intereses extrapatrimoniales, entonces ningún contrato los incorpora.

Pero, desde luego, no es así. Lo que sucede, más bien, es que, junto con esos contratos, parecen haber otros que, simplemente, no incorporan intereses patrimoniales ${ }^{69}$. En tercer lugar, junto a este núcleo configurado por los contratos que se encuentran en los dos extremos - contratos con claro contenido patrimonial y contratos con claro contenido extrapatrimonial- parece extenderse una amplia zona de penumbra en la que las cuestiones, a primera vista al menos, resultan bastante más ambiguas. Así, por ejemplo, hemos de cuestionarnos si un contrato de compraventa de inmueble involucra intereses extrapatrimoniales ${ }^{70}$. Algo semejante sucede con un mandato judicial ${ }^{71}$, con un contrato de tarjeta de crédito $^{72}$, con uno de depósito ${ }^{73}$, de educación ${ }^{74}$, de seguros ${ }^{75}$, con un contrato que obliga al deudor a estudiar los títulos necesarios para que el acreedor adquiera un inmueble ${ }^{76}$, un contrato de servicios telefónicos ${ }^{77}$, un contrato de construcción de vivien-

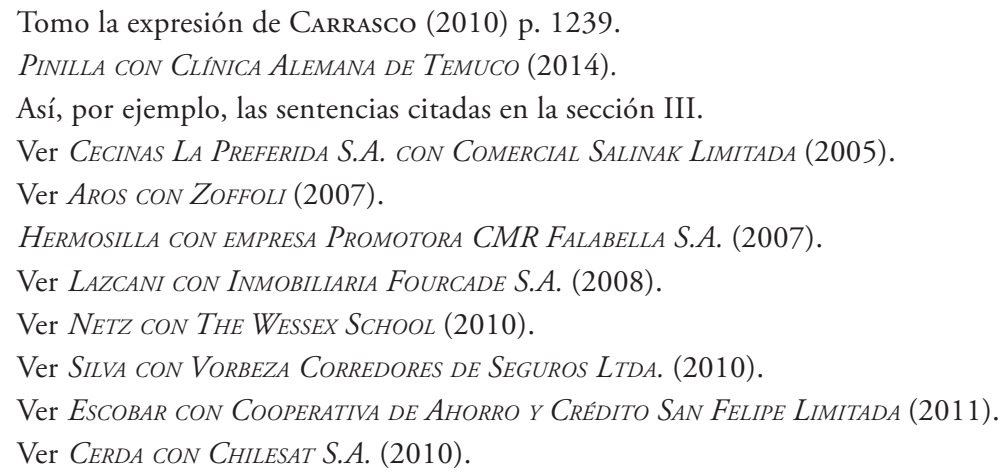


$\mathrm{da}^{78}$, uno de administración de buses ${ }^{79}$, de promesa de compraventa de un automóvil ${ }^{80}$, de compraventa de semillas ${ }^{81}$, de cuenta corriente $^{82}$, de práctica educacional ${ }^{83}$, de venta de automóvil ${ }^{84}$, de estacionamiento gratuito ${ }^{85}$, de transacción ${ }^{86}$, o de promesa de compraventa de inmueble ${ }^{87}$, de servicios educaciones universitarios ${ }^{88}$, de mutuo hipotecario ${ }^{89}$, de Isapre $^{90}$, entre muchos otros.

En todos estos casos -y otros más- se concedió indemnización por daño moral y, a veces, se trata de sumas relevantes ${ }^{91}$, pero ¿puede, sin más, afirmarse que todos ellos son contratos que involucran intereses extrapatrimoniales? La respuesta es, probablemente, no. $\mathrm{Y}$ es una respuesta que se justifica porque todo indica que los contratos pueden tener finalidades distintas y que estas no se pueden calibrar exclusivamente de manera abstracta, acudiendo al tipo contractual, sino que, además, debe prestarse atención a la situación en que tuvo lugar la contratación, el tipo de partes que se vincularon, etc.

\section{HACIA UNA APROXIMACIÓN MÁS CONSERVADORA DE LA PROCEDENCIA DEL DAÑO MORAL EN EL INCUMPLIMIENTO CONTRACTUAL: LA NOCIÓN DE DAÑO MORAL Y EL ÁMBITO DE RESGUARDO DEL CONTRATO COMO LIMITACIONES}

La sección anterior ha intentado mostrar que la respuesta de la Corte Suprema a la pregunta acerca de la procedencia del daño moral frente al incumplimiento contractual ha sido inflacionaria. Y ha argumentado que este carácter se explica por dos razones. La primera de ellas es una noción de daño moral extraordinariamente amplia. La segunda, es una general desaprensión por parte de la Corte respecto de la función limitadora del contrato. En esta sección se indican dos formas de limitar esa respuesta inflacionaria. La primera se refiere a la noción de daño moral, la segunda al ámbito de resguardo del contrato. Ambas cuestiones se examinan con cargo a la muestra de sentencias que ha empleado este trabajo $^{92}$.

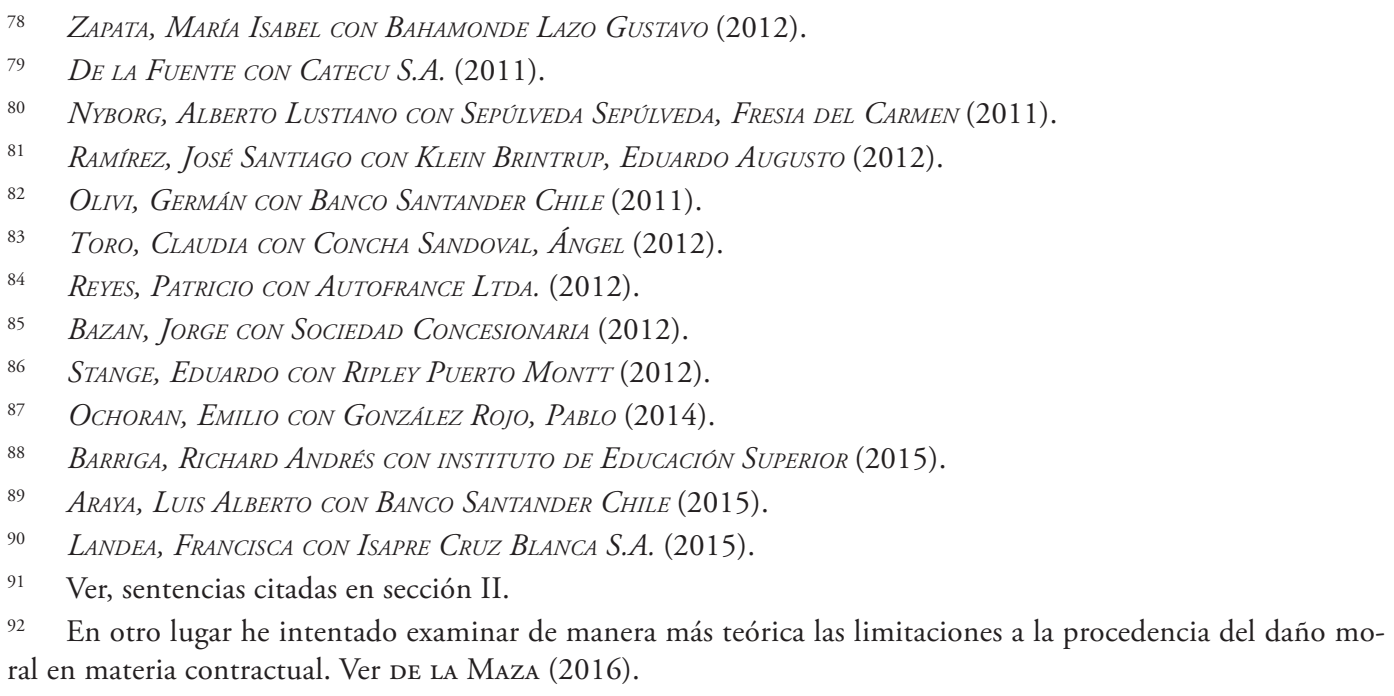




\subsection{A PROPÓSITO DE LA NOCIÓN DE DAÑO MORAL: UNA RESTRICCIÓN MINIMALISTA}

Si bien es cierto que, como ya ha quedado dicho, la noción de daño moral que emplea la Corte Suprema es extremadamente subjetiva resulta posible detectar algún caso en el que se ha señalado que aquello que se pretende afectado no llega a constituir daño moral. Convendrá detenerse un momento aquí.

La idea es elocuentemente desarrollada en un voto de minoría del ministro Oyarzún y el abogado integrante Domingo Hernández en una sentencia de 4 de julio de 2011 referente a un contrato de cuenta corriente ${ }^{93}$. En el caso, el demandante solicitó $\$ 400.000 .000$ por daño moral pues debido al incumplimiento que se reprocha al Banco demandado sufrió contratiempos por no poder pagar con cheques. Los disidentes estimaron que los supuestos daños morales: "solo se enmarcan dentro de los contornos de impresiones que, aunque negativas, no escapan de los parámetros esperables dentro de la vida de relación o en sociedad, pero que, en modo alguno se condicen con la entidad mínima de ese mal, perjuicio o aflicción en la psique o en las facultades espirituales que ha de concurrir en el sujeto que acciona para obtener su compensación" ${ }^{\text {"9 }}$.

La idea resulta extremadamente interesante: según los disidentes, el daño alegado tiene una "entidad mínima" que "no escapa de los parámetros esperables dentro de la vida o la relación en sociedad". Una idea que también puede encontrarse en tres recientes sentencias de la Corte de Apelaciones de Santiago en las que se rechazó el daño moral alegado por incumplimiento contractual, señalándose lo siguiente: “...tampoco existe en la especie, prueba alguna tendiente a demostrar que lo que se reclama a título de daño moral sea una afectación distinta a la simple molestia o perturbación propia de todo incumplimiento contractual. En tal sentido, conviene tener presente que la sola infracción de un contrato no da lugar a una reparación por daño moral porque la sola molestia, perturbación o desagrado que le genera al acreedor la transgresión no es suficiente para configurarlo como tal. De lo contrario, se llegaría al exceso de que todo incumplimiento en el marco mencionado generaría un daño moral, dado que esas consecuencias son propias a toda conculcación" 95 .

Entonces, aun si se acepta una noción de daño moral tan amplia como la de la Corte Suprema, resulta aconsejable, según lo ha indicado la doctrina, tanto a nivel nacional ${ }^{96}$ como en el extranjero ${ }^{97}$, limitarla mínimamente, excluyendo, generalmente al menos ${ }^{98}$, las simples molestias que, casi con toda seguridad, causará el incumplimiento de un contrato.

\footnotetext{
93 FRITZ CON BANCO SANTANDER CHILE (2011).

94 FRITZ CON BANCO SANTANDER CHILE (2011). Considerando 6.

95 Cifuentes, Andrés Ignacio con Automotriz Rosselot S.A. (2015), Considerando 2, voto disidente Silva, Juan Matías con Central Parking System Chile S.A. (2015) Considerando 3 y Vergara, Rodrigo con Latam AirLINES GROUP S.A. (2015) Considerando 6.

96 Ver, por ejemplo, VIDAL (2012) p. 649.

${ }_{97}$ Ver, por ejemplo, DíEz-Picazo (2008) pp. 85-93.

98 Digo "generalmente" porque siempre será posible que algún tipo de contrato, por sus circunstancias extremadamente peculiares (imaginemos uno cuyo objeto sea específicamente darle paz y seguridad al acreedor) aconseje indemnizar aún esta molestia.
} 


\subsection{El Ámbito de ResGuardo del CONTRATO}

Del hecho que la Corte Suprema generalmente no considere el contrato para evaluar la procedencia del daño moral, no significa que no lo haga nunca. Ahora se trata de ver cómo lo ha hecho en las ocasiones en que se ha dedicado a esta empresa.

Una primera cuestión que habrá que advertir es que no todas las sentencias lo hacen de la misma manera. En primer lugar, es posible identificar algunas que se ocupan de la cuestión de manera más bien tangencial. Así, por ejemplo, la sentencia de 28 de noviembre de 2006 sobre un contrato de prestaciones médicas, indica, a propósito del artículo 1556, que uno de los requisitos de la indemnización del daño moral es que el deudor "haya podido preverlo o haya actuado con culpa grave" 99 . En otra sentencia, también sobre prestaciones médicas, esta vez de 28 de enero de 2011, se establece, también a propósito del artículo 1556, que es requisito de esta partida indemnizatoria que el deudor "haya podido preverlo, actuando de modo diferente" ${ }^{100}$.

Existe un segundo grupo de sentencias al que conviene prestar mayor atención pues formulan de manera explícita la idea de que la previsibilidad constituye un dispositivo que limita la procedencia del daño moral en materia contractual. Y, como se verá a continuación, permiten deslindar dos nociones de previsibilidad.

La primera de las sentencias corresponde a la sentencia de 25 de marzo de $2008^{101}$, a propósito de responsabilidad médica por negligencia en una circuncisión, en cuyos considerando décimo y undécimo se lee lo siguiente: "Que en cuanto a la infracción del artículo 1556 del Código Civil, que se vincula con la circunstancia de que los sentenciadores concluyeron que es procedente la indemnización del daño moral en sede contractual sin que exista fundamento legal para ello, es preciso poner de relieve que, al contrario de lo que sostiene el recurrente, sí se admite la indemnización del daño moral en el ámbito de la responsabilidad contractual.

Este tribunal ha reconocido su pertinencia en esta esfera de responsabilidad, concediéndola, empero, solo en aquellos casos en que las obligaciones a que da lugar el negocio contractual de que se trata no se limitan exclusivamente al logro de resultados puramente materiales o patrimoniales.

En efecto, esta clase de resarcimiento procede únicamente en eventos en los que la convención extiende su ámbito al resguardo o protección de bienes extrapatrimoniales o cuando comprende intereses que claramente ya no conciernen al patrimonio sino a la personalidad moral del sujeto, como su afectividad, su estabilidad emocional, su integridad moral, etc.

Que de esta manera, entonces, es posible explicar que si de ordinario el incumplimiento en este ámbito solo lesiona de modo directo intereses económicos o concernientes al patrimonio del contratante acreedor, el Código Civil, en su artículo 1556, señale únicamente como rubros de lesión o detrimento a considerar en la avaluación judicial provo-

\footnotetext{
99 OCARANZA CON ROBINSON (2006).

100 FERNÁNDEZ CON E. KOVACS S.A. (2010).

101 ROCHET CON OKSENBERG Y CLINICA LAS NIEVES S.A. (2008).
} 
cada por tal incumplimiento el daño emergente y el lucro cesante, ambos de indiscutible carácter material.

Por el contrario, es posible afirmar que si el negocio afecta dirige no solo a derechos o intereses patrimoniales, su inejecución puede, causal y directamente, menoscabar derechos o intereses de una naturaleza puramente personal, propia de la intimidad del acreedor, circunstancia que hace posible el otorgamiento de una indemnización que repare el dolor o quebranto espiritual sufrido por el demandante..."102.

La segunda sentencia que conviene considerar es de 12 de abril de 2011, también sobre responsabilidad médica ${ }^{103}$. En su considerando décimo se lee lo siguiente: "Que el artículo 1556 del Código Civil no incluya en la indemnización de perjuicios al daño moral no impide su procedencia en el ámbito de la responsabilidad contractual, toda vez que dicha norma está referida a los daños patrimoniales. En el caso de autos, como puede advertirse, el objeto del contrato celebrado entre las partes es extrapatrimonial, de manera que su incumplimiento importa la posibilidad de indemnización de dicho rubro. Es un hecho establecido en la causa que el médico incumplió su deber de cuidado, provocando el daño que motivó esta demanda, de manera que resulta procedente la condena al pago de una indemnización por el daño moral causado a la actora, como lo resolvieron los jueces del fondo. En efecto, el artículo 1558 del Código Civil establece que si no se puede imputar dolo al deudor, cuyo es el caso de autos, este es responsable de los perjuicios que se previeron o pudieron preverse al tiempo del contrato. No cabe duda que en un contrato de prestación de servicios médicos, específicamente para la realización de una cirugía, como lo es una mamoplastía reductiva, está prevista la existencia del daño moral, en el caso que por alguna complicación de que el médico sea responsable resulte dañada la persona de la paciente" 104 .

En tercer lugar, puede considerarse la sentencia de 25 de octubre de 2012 sobre un caso de una operación de cálculos biliares ${ }^{105}$. En el considerando décimo se señala lo siguiente: "Que la sentencia recurrida no incurre en error de derecho al estimar, por una parte, que las lesiones sufridas por la demandante y que configuran el daño por el cual reclama indemnización, surgen como consecuencia inmediata y directa del incumplimiento de las obligaciones asumidas por el doctor Alcota en el contrato a que se ha hecho mención, y que el grado de culpa de que este respondía le imponía el deber de prever errores o negligencias como el que ocasionó la lesión, más aún si la misma naturaleza del vínculo contractual impone la obligación de seguridad que antes se mencionaba, que asegura la integridad de la persona que contrató el servicio; y, por otra, que la demandante sufrió un perjuicio extramatrimonial o daño moral, consistente en el dolor, angustia, sufrimiento, asimismo, plenamente previsible, y que los sentenciadores, dentro de las facultades que les otorga la ley, avaluaron en la suma de $\$ 3.000 .000 ” 106$.

102 ROCHET CON OKSENBERG Y CLINICA LAS NIEVES S.A. (2008). Considerando 10.

103 Peralta con Hospital Clínico Universidad de Chile (2011).

104 Peralta con Hospital Clínico Universidad de Chile (2011). Considerando 10.

105 ROJAS, YASNA CON FisCO DE CHILE Y OTRO (2012).

106 Rojas, YASNA CON FisCo DE CHILE Y OtRo (2012). Considerando 10. 
En cuarto lugar, puede prestarse atención a la sentencia de la Corte de 1 de octubre de 2012, que resuelve un caso de robo en un estacionamiento ${ }^{107}$. En ella se encuentran dos considerandos especialmente interesantes. El primero es el décimo. Su tenor es el siguiente: "Que estima este tribunal de casación que para analizar la procedencia del daño moral por la infracción de un contrato, no es suficiente, para descartarlo, la mera constatación de que la convención, por su naturaleza, no protege intereses extrapatrimoniales o comprende intereses que claramente pueden afectar a la personalidad del sujeto, sino que es menester detenerse en las particulares circunstancias y características en que se celebró el que vincula a las partes, pues de ellas fluirá la posibilidad de que la mencionada infracción provoque un daño extrapatrimonial" ${ }^{108}$.

El segundo considerando al que conviene prestar atención es el undécimo. En él se lee lo siguiente: "Que, no es posible desconocer que para cualquiera persona que estaciona un vehículo a cambio de pagar un precio, la ocurrencia del daño o robo que teme y que es lo que se representó como la necesidad que la indujo a contratar, no solo produce un daño material, sino que conlleva, asimismo, un sentimiento de molestia y frustración, más cuando ha sido víctima de un hecho particularmente violento y susceptible de provocar una natural emoción de perturbación y desagrado, que no incide en el aspecto patrimonial sino que en otro, completamente distinto al valor en dinero de los deterioros o especies robadas.

Tampoco cabe desconocer que para la contraparte de quien contrata la custodia del vehículo es plenamente previsible suponer que el deterioro o robo en este, que configura el incumplimiento de obligación, va a causar la molestia o aflicción que antes se mencionaba" 109 .

En quinto lugar, la sentencia de la Corte Suprema de 26 de septiembre de 2013 sobre incumplimiento de un contrato de construcción a suma alzada. "En efecto, esta clase de resarcimiento procede únicamente en eventos en que la convención extiende su ámbito al resguardo o protección de bienes extrapatrimoniales, o cuando comprende intereses que claramente ya no conciernen al patrimonio sino a la personalidad moral del sujeto, como su afectividad, su estabilidad emocional, su integridad moral, etc.

Segundo: Que de esta manera, entonces, es posible explicar que si de ordinario el incumplimiento en este orden solo lesiona de modo directo intereses económicos o concernientes al patrimonio del contratante acreedor, el Código Civil, en su artículo 1556, señale únicamente como rubros de lesión o detrimento a considerar en la avaluación judicial provocada por tal incumplimiento el daño emergente y el lucro cesante, ambos de indiscutible carácter material.

Por el contrario, es posible afirmar que si el negocio afecta no solo a derechos e intereses patrimoniales, su inejecución puede, causal y directamente, menoscabar derechos o intereses de una naturaleza puramente personal, propia de la intimidad del acreedor,

\footnotetext{
107 BAZAN, JoRgE CON SOCIEDAD CONCESIONARIA (2012).

108 BAZAN, Jorge CON SOCIEDAd ConCESIONARIA (2012), Considerando 10.

109 Bazan, Jorge con Sociedad Concesionaria (2012), Considerando 11.
} 
circunstancia que hace posible el otorgamiento de una indemnización que repare el dolor o quebranto espiritual sufrido por la demandada.

Que, en la especie, atendido el contenido y la naturaleza de la convención que origina la controversia - un contrato de ejecución de obras- las obligaciones a que ella dio lugar quedaron limitadas exclusivamente al resultado material de las mismas. Por ello, no resulta procedente acceder al daño moral solicitado por la actora en su demanda, como lo hizo la sentencia recurrida, pues en este caso no se dan los supuestos a que se ha hecho referencia en los motivos anteriores; y, en consecuencia, al acceder a su resarcimiento, los sentenciadores de la instancia han incurrido en una infracción del artículo 1556 del Código Civil, la que ha influido sustancialmente en lo dispositivo del fallo y que solo puede ser remediada mediante la invalidación del mismo. Y la consecuente sentencia de reemplazo" 110 .

En fin, en sexto lugar puede considerarse la sentencia sobre promesa de compraventa de inmueble de 10 de noviembre de 2014. Allí se lee: "Que dentro del estatuto de responsabilidad en estudio, el contratante incumplidor debe indemnizar el daño moral, si como sucede en este caso ha estado en situación de preverlo, atendiendo a criterios objetivos, en razón del contenido de la convención, de los pagos anticipados recibidos, las mejoras introducidas a la propiedad de la naturaleza de las obligaciones contraídas conforme a la buena fe, tanto más si se considera que el demandado no pudo menos que estar en conocimiento de no ser el dueño exclusivo de la propiedad que prometía vender" ${ }^{111}$.

En estas seis sentencias resulta evidente la importancia de la previsibilidad ex artículo 1558 como un dispositivo para limitar la procedencia del daño moral. Igualmente, según creo, resulta evidente que por "previsibilidad", se pueden entender dos cosas distintas ${ }^{112}$. La primera de ellas consiste en la posibilidad del deudor de representarse los daños que causará el incumplimiento del contrato. La segunda consiste en preguntarse si el deudor asumió el riesgo de esos daños. La diferencia entre las dos formas de concebir la previsibilidad puede capturarse si se comparan los argumentos del voto de mayoría en la sentencia recién citada de 1 de octubre de 2012 con el voto disidente de la ministra Maggi.

Como se recordará, en el voto mayoritario se señala lo siguiente: "Tampoco cabe desconocer que para la contraparte de quien contrata la custodia del vehículo es plenamente previsible suponer que el deterioro o robo en este, que configura el incumplimiento de obligación, va a causar la molestia o aflicción que antes se mencionaba"113.

La idea de previsibilidad parece funcionar aquí como la posibilidad de representarse el resultado dañoso.

En el voto disidente, en cambio, la ministra Maggi mira las cosas con mayor sutileza. En sus palabras: "Que no se discute ya en doctrina que es posible que el incumplimiento contractual pueda dar lugar a una indemnización por daño moral, si bien la respuesta acerca de la procedencia de la misma no puede formularse en términos absolutos,

110 Constructora Monteverde Ltda. con Ilustre Municipalidad de La Ligua (2013). Considerando 28.

111 Ochoran, Emilio con González Rojo, Pablo (2014). Considerando 8.

112 Sobre esto ver De la Maza (2016).

113 BAZAN, JoRge CON SOCIEDAD CONCESIONARIA (2012). Considerando 11. 
pues la naturaleza y el tipo específico de contrato serán relevantes a la hora de determinar si el menoscabo moral que se pretende derivado del incumplimiento de una obligación determinada resultaba o no previsible para los contratantes, es decir, si el acreedor de la indemnización que se demanda tomó a su cargo el riesgo de lesionar intereses extrapatrimoniales de su contraparte" 114 .

Ahora la previsibilidad no consiste, exactamente, en la posibilidad del deudor de representarse el daño moral que provocará el incumplimiento, sino en el hecho que ese deudor lo haya asumido. Y la pregunta, entonces, tendrá que ser ¿cómo saber si lo asumió o no? Los considerandos cuarto y sexto del voto disidente contribuyen a responder a esta pregunta. Convendrá prestarles atención: "Que, desde luego, la previsibilidad del daño es también exigible respecto de los perjuicios morales y al disponer la norma citada que el deudor es responsable "de los perjuicios que se previeron o pudieron preverse al tiempo del contrato", adscribe claramente al criterio que "entiende que el legislador ha querido comprender a todas aquellas consecuencias que normalmente se derivan del incumplimiento, ya sea por la naturaleza de la obligación o ya sea por las circunstancias que lo rodean. Justamente, al no depender del querer del deudor, se le conoce como "previsión objetiva”, en alusión también al sistema que se emplea en su determinación"115. En este contexto, la previsibilidad del daño podrá provenir de la propia naturaleza de la obligación contraída, si ella está directamente vinculada con intereses extrapecuniarios, o de las circunstancias que rodean la celebración del contrato, si estas conducen natural y razonablemente a suponer que el incumplimiento contractual acarreará consecuencias de orden extrapatrimonial (...)

Que los anteriores razonamientos conducen a concluir que dentro del estatuto de responsabilidad en estudio, el contratante incumplidor debe indemnizar el daño moral cuando ha estado en situación de preverlo al tiempo del contrato, atendiendo a criterios objetivos, sea en razón del contenido de la convención, de la naturaleza de las obligaciones contraídas conforme a la buena fe, o en atención a los riesgos que normalmente pueden derivar del incumplimiento. Ninguno de estos criterios concurre en el caso de autos, en que se trata de un contrato de carácter preponderantemente económico, como es el arrendamiento de un estacionamiento, en que la inobservancia de la obligación de custodia de un automóvil asumida por el arrendador, si bien lo obliga a resarcir todos los perjuicios materiales que de su falta de diligencia hayan derivado, no lo fuerza a responder de situaciones ajenas al contenido del contrato y que no pudo razonablemente prever, como el cuantioso menoscabo moral que al actor reclama a causa de "molestias laborales y de tiempo invertidas en la solución del problema”, circunstancias que, al margen de toda otra consideración, tampoco responden al concepto de daño moral elaborado por la doctrina y la jurisprudencia"116.

Según la opinión de la ministra Maggi lo determinante consiste en preguntarse si el deudor asumió el riesgo de la lesión de intereses extrapatrimoniales. En segundo lugar,

114 BAZAN, JORGE CON SOCIEDAD CONCESIONARIA (2012). Considerando 2.

115 Domínguez (2000) p. 541.

116 Ochoran, Emilio con González Rojo, Pablo (2014). Considerandos 4 y 6. 
para responder a esta pregunta señala que se debe considerar el contenido del contrato, la naturaleza de las obligaciones contraídas y los riesgos que, normalmente puedan derivar de su incumplimiento. Aplicando este test, la ministra Maggi concluye que el contrato de arrendamiento no protegía intereses extrapatrimoniales, por lo tanto, aun cuando se hayan afectado, están más allá del ámbito de resguardo del contrato y, por esa razón, no deben indemnizarse.

\section{3. ¿PARA QUÉ SIRVE El ÁMBITO DE RESGUARDo DEL CONTRATO?}

La respuesta a esta pregunta puede ser doble. De una parte sirve para sintonizar los fallos de la Corte Suprema con la opinión de la doctrina más autorizada. De otra parte, presta utilidad si se considera que los jueces deben tomarse en serio los contratos que celebran las partes.

Con algo de fortuna, exponer la opinión de la doctrina nacional al respecto debiese iluminar acerca de la necesidad de tomarse en serio el contrato al conceder $-\mathrm{O}$ no- indemnizaciones por daño moral.

En el ámbito nacional, actualmente al menos, la doctrina parece estar de acuerdo en dos cosas. La primera es que las indemnizaciones por daño moral proceden en materia contractual. La segunda es que las indemnizaciones por daño moral no necesariamente proceden por daño moral.

En otra parte, he intentado hacerme cargo de la opinión de la doctrina con respecto a la procedencia del daño moral en materia contractual ${ }^{117}$. Si vuelvo a considerar la cuestión aquí es únicamente para mostrar dos cosas. La primera de ellas es que, al menos, desde la mirada de la doctrina nacional no resulta aceptable una respuesta tan inflacionaria del daño moral como la que acabo de presentar. La segunda consiste en identificar con la mayor precisión posible la importancia que da la doctrina al contrato para considerar esta cuestión.

Por lo que toca a lo primero, aun una autora que ha manifestado abierta simpatía con la procedencia del daño moral en materia contractual como la profesora Carmen Domínguez ha señalado, con claridad, que no procede frente a cualquier incumplimiento; en sus palabras: “(...) aunque aboguemos por un claro reconocimiento del daño moral en esta esfera [la contractual] de la responsabilidad, creemos que ello no ha de suponer ni supone una indebida aplicación del ámbito del contrato que pueda conducirnos a una verdadera fantasía contractual. No se trata ciertamente de conceder esta índole de reparación por consecuencias no económicas remotas que de ninguna manera han podido entrar en el cálculo de riesgos del deudor. La infracción del contrato supone siempre molestias y desagrados, pero ello no significa que estos puedan y deban ser indemnizados como daño moral. Por el contrario, solo debe ser resarcido por vía contractual el perjuicio extrapatrimonial producido a resultas del incumplimiento y no ocasionalmente por él $(\ldots)^{118}$.

Lo que he denominado aquí una "respuesta liberal" corresponde a lo que lo profesora Domínguez identifica, en la obra más importante sobre la materia publicada en

117 De la Maza (2016)

118 Domínguez (2000) p. 355. 
Chile, como una "verdadera fantasía contractual.” Más adelante, la profesora Domínguez considera que la limitación del daño moral quedaría determinada por la exigencia de previsibilidad que configura el artículo 1558 del Código Civil ${ }^{119}$ y concluye que la justificación de la previsibilidad se encontraría en el respeto a la voluntad contractual ${ }^{120}$.

Por su parte, el profesor Ramón Domínguez considera, a propósito de un comentario de una sentencia de la Corte Suprema, que lo determinante consiste en fijar el "estricto ámbito contractual.” Sirviéndose de la distinción entre contratos personales y comerciales concluye:

"Un contrato de representación de una empresa productora de armamento y su ejecución por parte del representante no parece, en caso alguno, que pueda comprender dentro de su "ámbito" la consideración de intereses o situaciones no económicas en aquel sentido y que puedan ser "consecuencias virtualmente comprendidas en él", de modo que es imposible pretender que la falta de pago de las comisiones previstas pueda generar un daño moral" 121.

Jana y Tapia profundizan en esta línea, señalando lo siguiente:... en otros contratos (denominados por el Common Law, commercial contracts), por su naturaleza fundada esencialmente fundada en el intercambio comercial de bienes y servicios, resulta extraño a la naturaleza y riesgos tenidos a la vista por las partes al tiempo de contratar que el incumplimiento tenga consecuencias extrapatrimoniales para el acreedor" ${ }^{\prime 22}$.

Continúan dos autores prestando atención a la previsibilidad ex artículo 1558 e indican lo siguiente: "Esta idea, la de dar contenido a la noción de previsibilidad a partir de la noción de riesgo, pareciera ser un camino particularmente fértil para fijar el ámbito de los daños indemnizables. Así, la pregunta acerca de cuáles daños son previsibles y cuáles no, podría replantearse entonces desde la perspectiva de ¿a quién pertenece el riesgo que ocasiona el daño: ¿debe el daño ocurrido ser tratado como parte del riesgo de una parte o de la otra?" 123 .

Se encuentra en la misma línea Barros Bourie ${ }^{124}$, quien añade que existen algunos contratos que naturalmente involucran la protección de intereses extrapatrimoniales y que, en cambio, existen otros que resultan netamente comerciales ${ }^{125}$. En fin, recientemente, Vidal Olivares ha continuado por esta dirección, enfatizando el hecho de que, salvo en casos de culpa grave o dolo, el centro de gravedad de la cuestión se encuentra en la forma en que el contrato distribuye los riesgos ${ }^{126}$; la idea puede presentarse de la siguiente manera: "Para examinar los criterios o condiciones para la compensación del daño moral contractual es esencial tener en cuenta que la fuente de la obligación de indemnizar, cualquiera sea la naturaleza del daño, es el propio contrato entendido como mecanismo de

\footnotetext{
119 Domínguez (2000) pp. 489-591.

120 Domínguez (2000) p. 563

121 Domínguez (2000) p.176.

122 Jana y Tapia (2004) p. 193.

123 Domínguez (2000) p. 192.

124 Barros (2006) p. 343.

125 Barros (2006) pp. 343-344.

126 VidAL (2012) p. 770.
} 
reparto de riesgos entre las partes y que no prevé solo para el cumplimiento sino también para el evento de su infracción, imputando responsabilidad al deudor según tal reparto ${ }^{127}$.

Pues bien, frente a lo primero -las limitaciones del daño moral- no cabe duda, ninguno de los autores y autoras citadas $-\mathrm{y}$ otros más ${ }^{128}$ - promueve una procedencia irrestricta de la indemnización por daño moral. Por lo que toca a lo segundo -aquello que permite limitar la procedencia de la indemnización por daño moral- parece existir acuerdo en que, de una parte, se trata de la previsibilidad ex artículo 1558. De otra parte -y esto es lo que podría conjurar el riesgo de una aceptación inflacionaria del daño moral- la previsibilidad equivaldría a algo así como los riesgos asumidos por las partes al momento de contratar.

Esta parece ser la mirada de la doctrina. Como se ve, ha existido una reflexión acerca de las limitaciones del daño moral en sede contractual y en esa reflexión parece haber ocupado un lugar prominente el contrato y la forma en que distribuye los riesgos.

En otras palabras, frente a la cuestión de la limitación del daño moral, la doctrina ha respondido desde el contrato, señalando que la pregunta que debe formularse es si el deudor ha asumido o no el riesgo de un daño moral derivado del incumplimiento de sus obligaciones. Si lo ha hecho, entonces debe indemnizarlo, en caso contrario, aun cuando el incumplimiento pueda haber lesionado un interés extrapatrimonial, no debe indemnizarlo.

Pues bien, el resumen de esta cuarta sección es el siguiente. Si bien, mayoritariamente, la Corte Suprema ha respondido de manera inflacionaria a la pregunta acerca de la procedencia del daño moral, es posible detectar algunos casos -en ocasiones, de manera extremadamente marginal- en los cuales aparecen dispositivos para controlar la procedencia del daño moral. En primer lugar, una noción mínimamente restrictiva del daño moral que elimine las molestias o inconvenientes que, inevitablemente, genera un incumplimiento contractual. En segundo lugar, acudir al ámbito de resguardo del contrato, preguntándose acerca de si cubría o no intereses extrapatrimoniales.

\section{ALGUNAS APLICACIONES}

Ante todo, acudir a la noción de daño moral y al ámbito de resguardo del contrato mejora la práctica argumentativa que, con cierta frecuencia, es posible percibir en las sentencias nacionales. Al menos en aquellas en donde la discusión se limita a determinar si existió incumplimiento o no y, en caso de haberlo existido, si este causó la lesión de un interés extrapatrimonial.

Desde luego, eso es necesario. Pero, lo que argumenta este trabajo es que no es suficiente. Aun se pueden añadir dos preguntas que contribuyen a tornar más reflexiva la práctica argumentativa de los litigantes y la de los jueces. La primera de ellas es si aquello que se alega como afectado queda cubierto por la noción del daño moral y para hacer esto

127 Barros (2006) p. 644

128 Ver, por ejemplo, Cárdenas (2004) p. 385, Barrientos (2007) pp. 7-22 y Rutherford (2013) p. 682. 
parece necesario identificar con algún grado de exactitud qué es lo que se afectó. La segunda es si aquello que se estima afectado se encontraba protegido por el contrato.

Pues bien, el objetivo de esta última sección consiste en intentar aplicar en algunos casos esta noción mínimamente restrictiva del daño moral y la idea de ámbito de resguardo del contrato con el objeto de limitar o racionalizar el uso de que ha hecho la Corte Suprema de esta partida indemnizatoria tratándose de incumplimiento contractual.

\subsection{El NÚCleO}

Lo que he denominado el "núcleo" se encuentra conformado por casos que se sitúan en dos extremos. El primero de esos extremos es aquel en que, claramente, el ámbito de resguardo del contrato involucra intereses extrapatrimoniales. El segundo corresponde a aquel que, claramente, no los involucra.

Aquí, probablemente, se pueda emplear una distinción bien establecida en el common law ${ }^{129}$, que debe diferenciarse entre contratos personales y comerciales ${ }^{130}$. La idea que se encuentra detrás de esta distinción es que los contratos comerciales se celebran para garantizar algún tipo de beneficio patrimonial como aquellos que son propios de la actividad de los comerciantes, o bien cuando se trata de obtener alguna ganancia en dinero o aumentar el patrimonio ${ }^{131}$.

En este sentido, los contratos que involucran servicios médicos son personales; la razón es que, típicamente, al menos una de las prestaciones no tiene por objeto favorecer el patrimonio de su acreedor, sino que, de manera absolutamente predominante, intereses de carácter extrapatrimonial.

De esta manera, en este tipo de contratos puede asumirse con cierta tranquilidad la idea de la Corte Suprema respecto a una especie de "principio general" de daño moral a la que me referido más atrás en este trabajo. Algo así como una presunción iuris tantum de daño moral. Considerando la muestra de sentencias con las que se ha trabajado, algo semejante puede suceder en contratos de servicios educacionales. O bien, para utilizar algún desarrollo del derecho estadounidense en servicios relacionados con difuntos, contratos que involucran objetos de valor sentimental en los que la prestación de alguna de las partes tiene por objeto proveer de felicidad o seguridad a la otra como sucede, por ejemplo, con un contrato de servicios vacacionales o uno de seguros ${ }^{132}$.

En el otro extremo se ubican los contratos comerciales. Y lo que sucede aquí es, exactamente, lo contrario: no debe asumirse un "principio general" de daño moral, sino, exactamente, lo contrario, en términos tales que la indemnización del daño moral debe resultar extremadamente excepcional. Es probable que esto último no resulte discutible, lo que se puede presentar a discusión es, de una parte, cuáles contratos son comerciales y, de otra, qué circunstancias determinan que, excepcionalmente, en estos contratos se indemnice el daño moral.

\footnotetext{
129 Ver, por ejemplo, Goldberg (1986) pp. 61-67.

130 Domínguez (2000) p. 176.

131 Goldberg (1986) p. 64.

132 Goldberg (1986) pp. 60-61.
} 
Una respuesta detallada a esas dos preguntas excede las posibilidades de este trabajo, sin embargo, pueden afirmarse dos cosas. La primera es que, si el contrato tiene por objeto utilizar aquello que de él se obtenga para recolocarlo de alguna manera en el mercado y obtener ganancias, es comercial. La segunda es que, al menos en el ámbito chileno, una circunstancia excepcional queda configurada porque una de las partes termine figurando en un registro comercial ${ }^{133}$.

\subsection{EN LA PENUMBRA, INTERESES MÚlTiPLES: EL CASO DE LOS CONTRATOS BANCARIOS}

Más allá del núcleo existen contratos en los cuales, todo indica, se presenta cohabitación entre intereses patrimoniales y otros de carácter extrapatrimonial. La existencia de esta cohabitación puede acreditarse acudiendo a las funciones típicas de dichos contratos. En otras palabras, en lo que interesa al interés patrimonial, sucede que este tiene una cercana relación con alguna de las funciones típicas del contrato.

De la muestra de sentencias que se ha utilizado para este trabajo, probablemente el ámbito que pueda contribuir a mostrar esto con mayor elocuencia sea el de algunos contratos bancarios. Y utilizó la expresión "contratos bancarios" para referirme a aquellos contratos en los que participa un banco ejecutando una prestación propia de su giro.

La pregunta que debe formularse es si contratos como el mutuo, la hipoteca y el de cuenta corriente son contratos comerciales. Si lo son, entonces existe un problema, pues, existe un número importante en el cual la Corte Suprema ha concedido indemnizaciones por daño moral. De ellos, los más numerosos son los que, de alguna manera, involucran una cuenta corriente, a veces con independencia de otros contratos y otras en relación a mutuos o hipotecas ${ }^{134}$.

Se trata en estos casos de contratos con un evidente contenido patrimonial ¿por qué, entonces, los tribunales conceden indemnización por daño moral? En las sentencias que se han examinado no existe una reflexión acerca de por qué esos contratos incorporan dentro de su ámbito de resguardo intereses de carácter extrapatrimonial. La reflexión, cuando existe, se presenta más bien respecto a por qué el incumplimiento causó un daño moral. Y, el problema, es que, en algunos casos, parece ser que el daño moral se explica únicamente por las molestias que ha causado al acreedor el incumplimiento. Así, por ejemplo, en la sentencia de 21 de octubre de 2010, referido a un contrato de cuenta corriente en el que banco debitó al cliente una cantidad de dinero por un mutuo inexistente: “(...) corresponde dilucidar si el incumplimiento atribuido a la entidad bancaria ha importado menoscabo de tipo moral al actor, resultando notorio al efecto que la determinación del demandado, en orden de descontar de la cuenta corriente la suma de 187.840, corresponden al primer dividendo de un mutuo inexistente y haber enviado los avisos de vencimiento de la segunda cuota, le ocasionó a este sin duda, aflicción, amargura, ansia y preocupación (...)"135.

133 Ver el número siguiente.

134 HERRERA CON BANCO SANTANDER S.A. (2009).

135 Meriño con Banco Santander Santiago (2010). Considerando 6. 
Algo semejante sucede en la sentencia de 11 de abril de 2011 que falla un caso relativo a un contrato de depósito en el que el banco, sin autorización del depositante, entregó el dinero a un tercero ${ }^{136}$. La Corte se limita a considerar que el daño moral consistiría en la "duda, aflicción, amargura, ansia y preocupación" que le causó al acreedor el incumplimiento.

Pues bien, el problema es que si existe daño moral cada vez que el incumplimiento causa duda, aflicción, amargura, ansia y preocupación al acreedor, lo cierto es que cualquier incumplimiento contractual debería determinar la procedencia del daño moral.

Sin embargo, al considerar otros contratos, se advierte que el daño moral es una cuestión distinta a las simples molestias o perturbaciones que casusa el incumplimiento. El problema es que a consecuencia del incumplimiento del banco, la persona ha terminado en un registro de deudores morosos. Y, al suceder esto, podría argumentarse, se ha lesionado un interés extrapatrimonial, algo así como alguna dimensión de la honra de la persona $^{137}$. En este sentido, por ejemplo, en la sentencia de 25 de enero de 2011 sobre un incumplimiento de contrato de cuenta corriente ${ }^{138}$ que determinó el protesto de un cheque de la cuentacorrentista y el no pago de cotizaciones previsionales y de la salud, la Corte considera que dicho incumplimiento causó "descrédito, desprestigio y deshonra" y que se afectó "gravemente el prestigio comercial, el honor y otros ítem que impliquen de por sí una afectación de la persona humana. Algo semejante sucede en la sentencia de 31 de enero de 2012 en el que la Corte señala que el incumplimiento del banco que determinó la inclusión del demandante en un registro de deudores morosos habría "afectado su derecho a la honra"139. En el mismo sentido, la sentencia de 30 de marzo de 2012 sobre terminación de cuenta corriente ${ }^{140}$, considera que este hecho, sumado al envío de los antecedentes del deudor a DICOM, le causó "angustia, impotencia y descrédito".

Al pensar las cosas de esta manera, se salva el problema de la noción del daño moral asociada a cualquier sentimiento de malestar que cause el incumplimiento contractual. Pero queda un segundo problema, que puede formularse en los siguientes términos ¿por qué puede afirmarse que ese derecho se encuentra dentro del ámbito de resguardo de contratos como estos?

Una posible respuesta es porque contratos como la cuenta corriente tienen como una función típica el pago de obligaciones del cuentacorrentista y esta función se encuentra cercanamente relacionada con lo que podría denominarse su "honra comercial"141. De

\footnotetext{
136 PÉREZ CON BANCO CITIBANK S.A. (2011).

137 GARCÍA CON SCOTIABANK (2008).

138 Escobar con Cooperativa de Ahorro y CRÉdto SAN Felipe Limitada (2011).

139 CAMPOS CON BANCO SANTANDER CHILE (2011).

140 OLIVI, GERMÁN CON BANCO SANTANDER CHILE (2011).

141 Aun cuando no se trata de un contrato bancario, la importancia de la honra para la Corte Suprema $-\mathrm{y}$ su lesión a través de la inclusión injustificada en registros de deudores morosos- puede percibirse con toda claridad en la sentencia Stange, EDUARdo con Ripley PUERTO MontT (2012). Se trata del incumplimiento de un contrato de avenimiento respecto de una tarjeta de crédito entre una multitienda y un particular. Producto del incumplimiento de la multitienda el particular fue incluido en un registro de deudores morosos. La opinión de la Corte respecto del dańo moral fue la siguiente: "Que conforme a todo lo reseñado, no cabe duda que el incumplimiento imputable al demandado lesionó la integridad psíquica del demandante, por cuanto de manera arbitra-
} 
esta manera -si se acepta que ese es un interés extrapatrimonial- habrá que aceptar que la estrecha conexión que existe el interés extrapatrimonial cuya lesión se alega y una de las funciones típicas del contrato de cuenta corriente determina que deba entenderse que ese interés extrapatrimonial se encuentra cubierto por el ámbito de resguardo del contrato.

\subsection{Sincerar la justificación}

Existen otros tipos de contratos en los cuales las prestaciones de las partes tienen contenido patrimonial como el contrato de promesa de venta ${ }^{142}$, la venta ${ }^{143}$ o el arrendamiento ${ }^{144}$ respecto de los cuales la Corte ha concedido daño moral. Desde luego no es posible racionalizar todos ellos acudiendo a una noción relativamente restringida de daño moral o al ámbito de resguardo del contrato.

Sin embargo, al menos respecto de algunos de ellos es posible, por así decirlo, sincerar la justificación. Una posible lectura, es que, aunque de manera más bien inadvertida, la Corte no tenga necesidad de acudir al ámbito de resguardo del contrato pues lo que, realmente, sucede es que, al comportarse de manera especialmente reprochable, el deudor se ha puesto más allá del ámbito de protección del contrato y, de esta manera, responde por la lesión de intereses extrapatrimoniales, aun cuando estos, originalmente, no quedaran cubiertos por el ámbito de resguardo del contrato.

Para considerar esta idea, resulta necesario comenzar recordando que la previsibilidad únicamente limita el monto de los perjuicios - , por lo mismo, protege al deudorcuando el incumplimiento contractual no ha sido doloso ${ }^{145}$. Por lo mismo, si el incumplimiento ha sido doloso no tiene demasiado sentido preguntarse por el ámbito de resguardo del contrato pues lo que sucede es que el dolo le impide al deudor servirse de ese ámbito para alegar que el daño moral no estaba cubierto por el contrato.

Esta idea presta interés para evaluar la práctica argumentativa de la Corte en algunos casos en que, aparentemente, el ámbito de resguardo del contrato no considera intereses extrapatrimoniales y, sin embargo, se concede indemnización por daño moral.

Así, por ejemplo, en la sentencia de 3 de julio de 2007 sobre incumplimiento de contrato de tarjeta de crédito $^{146}$, la Corte conoce de un caso de hurto de la tarjeta en el cual, no obstante el hecho de que la tarjetahabiente comunicó el hurto, la multitienda mantuvo el cargo, le requirió el pago de dicho cargo, dio aviso al sistema de morosidad, llenó un pagaré por el total de la deuda y lo protestó, iniciando, además, el juicio ejecutivo.

ria, es decir, sin causa, y no obstante haber cumplido con el acuerdo a que las partes habían arribado, procedió a autoasignarse la vigencia de un crédito en mora por una suma ya condonada, afectando así el derecho a la honra, al incluirlo en el boletín de informaciones comerciales, con conocimiento que el actor por dedicarse a la vida comercial, las consecuencias que ello le acarrearía, implicaban la privación de acceso a créditos de toda clase, presentándose, de esta manera, como una persona morosa en sus obligaciones crediticias".

142 Sobre otro caso semejante ver Corte Suprema sentencia de 11 de junio de 2015 (rol 26846-2014). Venegas CAstro Jaime Guillermo con InMobiliaria Río TRANCURA (2009).

143 NúñEz, María de LOS ÁNGELES CON IGOR VLAdIMIR TAPIA TORRES (2010).

144 Ver Castillo con Sociedad InMobiliaria Mall Calama S.A. (2008).

145 Ver, por ejemplo, Vidal (2012) pp. 657-660.

146 Hermosilla con empresa Promotora CMR FaLABelLa S.A. (2007). 
En segundo lugar, puede considerarse la sentencia de 2 de septiembre de 2008 que recae sobre un caso de incumplimiento de contrato de arrendamiento de un inmueble comercial $^{147}$. El razonamiento de la Corte para conceder la indemnización por daño moral es el siguiente: "Consta que la actora, termina la sentencia, ha sufrido un menoscabo moral y personal, constituido por las aflicciones y preocupaciones provocadas a partir de su acción positiva de haber incurrido, en el convencimiento de contar con un contrato que le permitiría obtener su sustento a través de una serie de gestiones tendientes a desarrollar una actividad económica con respeto a las normas contractuales, administrativas, tributarias y sanitarias, que la demandada le impidió ejecutar, unilateralmente, sin justificación, habiendo sido sujeto de fuerza física en su persona y bienes e incluso de desalojos a plena luz del día y ante la vista y presencia de terceros, de modo que se tiene por acreditada la existencia de un daño moral para la demandante, el que será determinado en su monto de manera prudencial en la parte resolutiva, como paliativo del perjuicio extrapatrimonial por ella sufrido" 148 .

En tercer lugar, la sentencia de 30 de diciembre de $2011^{149}$ conoce de un caso de un contrato de promesa de compraventa de un vehículo motorizado en el cual se entregó al promitente vendedor la camioneta quien, por su parte, pagó el precio. Luego, sin embargo, el promitente vendedor se negó a cumplir el contrato prometido y sustrajo la camioneta mientras el promitente comprador la mantenía estacionada. Dentro de los hechos acreditados la Corte consideró que: "El actor a propósito del incumplimiento contractual (...) padeció una serie de inconvenientes, malos ratos, problemas y sufrimientos que le han provocado una fuerte depresión y desavenencias conyugales"150.

En cuarto lugar, en la sentencia de 10 de noviembre de 2014 sobre incumplimiento de contrato de promesa de compraventa se inmueble se lee lo siguiente: "Que dentro del estatuto de responsabilidad en estudio, el contratante incumplidor debe indemnizar el daño moral, si como sucede en este caso ha estado en situación de preverlo, atendiendo a criterios objetivos en razón del contenido de la convención, de los pagos anticipados recibidos, las mejoras introducidas a la propiedad, de la naturaleza de las obligaciones contraídas conforme a la buena fe, tanto más si se considera que el demandado no pudo menos que estar en conocimiento de no ser el dueño exclusivo de la propiedad"151.

Pues bien, se trata de casos diversos, sin embargo, hay algo común en ellos. Y aquello que parece común no es que el daño moral haya sido previsible en el sentido en que las partes pudieran representárselo al celebrar el contrato o en el sentido de que se entienda protegido por el ámbito de resguardo del contrato. De hecho, en el caso del arrendamiento del local comercial, no debiese caber duda de que es un contrato comercial.

Lo que, en cambio, parece extraordinariamente evidente es que en los cuatro casos los incumplimientos aparecen como especialmente reprochables. En todos ellos hay cir-

147 Castillo con Sociedad InMobiliaria Mall Calama S.A. (2008).

148 Castillo con Sociedad Inmobiliaria Mall Calama S.A. (2008). Considerando 2

149 Nyborg, Alberto Lustiano con SepúllVeda Sepúlveda, Fresia del Carmen (2011). Considerando 9.

150 Nyborg, Alberto Lustiano con Sepúlveda Sepúlveda, Fresia del Carmen (2011).

151 Ochoran, Emilio con González Rojo, Pablo (2014). Considerando 8. 
cunstancias que cualifican especialmente el incumplimiento. Bajo esas condiciones, una línea argumental más persuasiva para justificar la indemnización del daño moral consiste en afirmar que existiendo un incumplimiento doloso deben indemnizarse todos los perjuicios, aun si no se encuentran comprendidos dentro del ámbito de resguardo del contrato pues, al comportarse dolosamente, el deudor no se encuentra protegido por el contrato.

\section{CONCLUSIÓN}

Mutatis mutandis, la famosa frase de Oscar Wilde -a estas alturas, un lugar comúnsegún la cual "La verdad rara vez es pura y nunca simple" parece adecuada a la indemnización del daño moral en materia contractual en las sentencias de la Corte Suprema. Rara vez aparece con pureza por qué debe indemnizarse el daño moral frente a un incumplimiento contractual y las veces que aparece, no es simple hacerlo.

Esto no significa que deba renunciarse a la empresa de justificar adecuadamente esa indemnización, sino, precisamente, todo lo contrario. Este trabajo constituye un modesto esfuerzo de mostrar la necesidad de hacerlo y cómo hacerlo.

La idea es que en el escenario en que comenzó a situarnos la sentencia de la Corte suprema de 20 de octubre de 1994 resulta perentorio un intento de controlar la liberalización del daño moral frente al incumplimiento contractual. La sugerencia es que ese intento puede enderezarse, por una parte, reconsiderando, de manera más bien minimalista, la amplitud de la noción de daño moral. Por otra, se sugiere, prestar atención al ámbito de resguardo del contrato, y se muestran algunas aplicaciones de lo anterior. Proceder de esta manera no supone alejarse del derecho de contratos, sino, más bien, aproximarse a él. Después de todo, las exigencias que impone son dos: que el daño tenga cierta significancia y que nos tomemos en serio la distribución de los riesgos que las partes -o el legislador supletoriamente- decidieron en el contrato. Nada nuevo bajo el derecho de contratos.

Esto, desde luego, no agota los problemas que suscita la cuestión, pero quizás sea un comienzo promisorio para enfrentar algunos de ellos que, hasta ahora, no parecen haberse discutido suficientemente en el ámbito nacional.

\section{BIBLIOGRAFÍA CITADA}

Barrientos Zamorano, Marcelo (2007): "Los daños extrapatrimoniales que se previeron o pudieron preverse al tiempo del contrato", Revista Chilena de Derecho, vol. 34, No 1: pp. 7-22.

Barrientos Zamorano, Marcelo (2008): "Del daño moral al daño extrapatrimonial: la superación del pretium doloris”, Revista Chilena de Derecho, vol. 35, No 1: pp. 85-106.

Barros Bourie, Enrique (2006): Tratado de responsabilidad extracontractual (Santiago, Editorial Jurídica de Chile).

Cárdenas Villarreal, Hugo (2004): "Sobre la extensión de la reparación del daño moral derivado de contrato", Revista Chilena de Derecho, vol. 31, No 2: pp. 379-387.

Carrasco Perera, Ángel (2010): Derecho de contratos (Navarra, Thomson Reuters). 
De la Maza Gazmuri, Iñigo (2016): "Prever y asegurar", en AA.VV, Estudios de Derecho Civil XI (Santiago, Thomson Reuters) pp. 553-584.

Díez-Picazo, Luis (2008): El escándalo del daño moral (Madrid, Civitas).

Domínguez Águila, Ramón (2000): "Responsabilidad contractual. Ausencia de daño moral”, Revista de Derecho Universidad de Concepción, vol. 207: pp. 173-177.

Domínguez Hidalgo, Carmen (2000): El daño moral (Santiago, Editorial Jurídica de Chile).

Domínguez Hidalgo, Carmen (2006): "La reparación del daño moral derivado del contrato en el derecho civil chileno: realidad y límites", en Cuadernos de Análisis Jurídicos, Colección Derecho Privado, Tomo III (Editorial Fundación Fernando Fueyo L., Santiago) pp. 227-244.

Goldberg, Charlotte (1986): "Emotional Distress Damages and Breach of Contract: A New Approach”, U.C. Davis, Law Review, vol. 20: pp. 57-104.

Jana Linetzky, Andrés y Tapia Rodríguez, Mauricio (2004): "Daño moral en la responsabilidad contractual a propósito de un fallo de la Corte Suprema de 5 de noviembre de 2001", en Cuadernos de Análisis Jurídicos, Colección Derecho Privado, Tomo I (Editorial Fundación Fernando Fueyo L., Santiago) pp. 171-209.

Kramer, Adam (2014): The Law of Contract Damages (Londres, Hart).

PALmER, Valentine (2015): "European contractual regimes: The contemporary approach", en The Recovery of Non-Pecuniary Loss in European Contract Law (Cambridge, Cambridge University Press) pp. 95-110.

Rutherford Parentti, Romy (2013) "La reparación del daño moral derivado del incumplimiento contractual. Tendencia en la reciente jurisprudencia nacional y española", Revista Chilena de Derecho, vol. 40, No 2: pp. 669-689.

Vidal Olivares, Álvaro (2012): “Criterios para la procedencia de la indemnización del daño moral por incumplimiento contractual. Una mirada desde el derecho contractual”, en Domínguez, Carmen et al. (coords.), Estudios de derecho civil, Tomo VI (Thomson Reuters, Santiago) pp. 763-780.

\section{JURISPRUDENCIA CITADA}

Alarcón y otros con Empresa Constructora Emasil S.A. (2008) Corte Suprema, 25 de septiembre de 2008 (incumplimiento contrato de compraventa y daño moral). Rol 592007. Disponible en http://www.pjud.cl [fecha visita 12 de diciembre de 2016].

ANDRADE CON JARDIN INFANTIL APRENDER JUGANDO (2015): Corte Suprema, 13 de octubre de 2015 (incumplimiento contrato de compraventa e indemnización por daño moral). Rol 11382-2015. Disponible en http://www.pjud.cl [fecha visita 8 de julio de 2016].

Araya, Luis Alberto con Banco Santander Chile (2015), Corte Suprema, 9 de diciembre de 2015 (incumplimiento de contrato de mutuo hipotecario e indemnización de daño moral). Rol 5836-2015. Disponible en http://www.pjud.cl [fecha visita 8 de julio de 2016]. 
AROS CON ZOFFOLI (2007): Corte Suprema, 11 de abril de 2007 (incumplimiento contrato de mandato y daño moral). Rol 3291-2005. Disponible en http://www.pjud.cl [fecha visita 6 de diciembre de 2016].

Barriga, Richard Andrés con instituto de Educación Superior (2015), Corte Suprema, 14 de octubre de 2015 (incumplimiento de contrato de servicios educacionales e indemnización por daño moral). Rol 5909-2015. Disponible en http://www.pjud.cl [fecha visita 8 de julio de 2016].

BAZAN, Jorge CON Sociedad ConCESIONARIa (2012), Corte Suprema, 1 de octubre de 2012 (incumplimiento contrato de estacionamiento y daño moral). Rol 4415-2010. Disponible en http://www.pjud.cl [fecha visita 5 de julio de 2016].

Campos con Banco Santander Chile (2011), Corte Suprema, 17 de junio de 2011 (incumplimiento contrato de cuenta corriente e indemnización de perjuicios). Rol 57952011. Disponible en http://www.pjud.cl [fecha visita 12 de julio de 2016].

CAR S.A. con SAez Zambrano Julia (2013), Corte de Apelaciones de Concepción, 14 de junio de 2013 (derecho de retracto, ley 19.496). Disponible en http://www.pjud.cl [fecha visita 4 de julio de 2016].

Canet con Colegio Salesiano Valparaíso (2009): Corte Suprema, 4 de noviembre de 2009 (incumplimiento de contrato de prestación de servicios educacionales e indemnización por daño moral). Rol 7974-2009. Disponible en http://www.pjud.cl [fecha visita 4 de julio de 2016].

Castillo con Sociedad Inmobiliaria Mall Calama S.A. (2008): Corte Suprema, 2 de septiembre de 2008 (incumplimiento contrato de arrendamiento, daño moral). Rol 17272008. Disponible en http://www.pjud.cl [fecha visita 12 de diciembre de 2016]

Cecinas La Preferida S.A. con Comercial Salinak Limitada (2005): Corte Suprema, 27 de julio de 2005 (incumplimiento contrato de compraventa y daño moral). Rol 53202003. Disponible en http://www.pjud.cl [fecha visita 12 de diciembre de 2016].

CERda CON ChILesat S.A. (2010), Corte Suprema, 25 de enero de 2010 (incumplimiento de contrato de prestación de servicios telefónicos e indemnización por daño moral). Rol 3912-2010. Disponible en http://www.pjud.cl [fecha visita 12 de julio de 2016].

Cifuentes, Andrés Ignacio con Automotriz Rosselot S.A. (2015), Corte de Apelaciones de Santiago, 23 de enero de 2015 (incumplimiento contrato de compraventa e indemnización por daño moral). Rol 1552-2014. Disponible en http://www.pjud.cl [fecha visita 8 de julio de 2016].

Constructora Monteverde Ltda. con Ilustre Municipalidad de La Ligua (2013), Corte Suprema, 1 de octubre de 2013 (incumplimiento de contrato de construcción a suma alzada). Rol 375-2013. Disponible en http://www.pjud.cl [fecha visita 12 de diciembre de 2016].

Cruz, Mabel con Banco Santander Chile (2013), Corte de Apelaciones de Concepción, 1 de julio de 2013 (incumplimiento contrato de cuenta corriente e indemnización por daño moral). Rol 69-2013. Disponible en http://www.pjud.cl [fecha visita 8 de julio de 2016]. 
De la Fuente con CATECU S.A. (2011), Corte Suprema, 8 de agosto de 2011 (incumplimiento contrato de administración de buses e indemnización de perjuicios). Rol 37582011. Disponible en http://www.pjud.cl [fecha visita 12 de julio de 2016].

De la Torre con Chomali (2011): Corte Suprema, 20 de octubre de 2011 (incumplimiento contrato de construcción e indemnización de perjuicios por daño moral). Rol 9178-2010.

Díaz con Colegio Hispanochileno El Pilar (2015): Corte suprema, 7 de octubre de 2015 (acción de responsabilidad contractual). Rol 13190-2015. Disponible en http://www. pjud.cl [fecha visita 12 de julio de 2016].

Escobar con Cooperativa de Ahorro y CRÉdto SAN FELIPe Limitada (2011), Corte Suprema, 19 de enero de 2011 (incumplimiento de contrato de mutuo e indemnización por daño moral). Rol 3992-2011. Disponible en http://www.pjud.cl [fecha visita 8 de julio de 2016].

FERNÁNDEZ CON E. KoVACS S.A. (2010), Corte Suprema, 25 de mayo de 2010 (incumplimiento de contrato de compraventa e indemnización por daño moral). Rol 58492009. Disponible en http://www.pjud.cl [fecha visita 12 de julio de 2016].

FREIRE CON ISAPRE BANMÉDICA S.A. (2015): Corte Suprema, 21 de octubre de 2015 (incumplimiento de contrato de Isapre e indemnización por daño moral). Rol 146232015. Disponible en http://www.pjud.cl [fecha visita 8 de julio de 2016].

FRITZ CON BANCO SANTANDER CHILE (2011), Corte Suprema, 8 de julio de 2011 (incumplimiento contrato de cuenta corriente e indemnización de perjuicios por daño moral). Rol 137-2010. Disponible en http://www.pjud.cl [fecha visita 8 de julio de 2016].

GARCÍA CON SCOTIABANK (2008), Corte Suprema, 14 de octubre de 2008 (Incumplimiento contrato de mutuo e indemnización por daño moral). Rol 4078-2007. Disponible en http://www.pjud.cl [fecha visita 9 de julio de 2016].

Herrera con Banco Santander S.A. (2009), Corte Suprema, 7 de septiembre de 2009 (incumplimiento de contrato de cuenta corriente e indemnización por daño moral). Rol 1870-2008. Disponible en http://www.pjud.cl [fecha visita 12 de julio de 2016].

Hermosilla con empresa Promotora CMR Falabella S.A. (2007): Corte Suprema, 3 de julio de 2007 (incumplimiento contrato de tarjeta de crédito y daño moral). Rol 39012005. Disponible en http://www.pjud.cl [fecha visita 12 de julio de 2016].

Hugo Ruiz Ruiz; con laboratorio Biológico S.A. y otros (2001). Corte Suprema, 5 de noviembre de 2011 (incumplimiento de contrato de servicios y daño moral). Rol 1368-2000. LegalPublishing. Cita online CL/JUR/4636/2001.

larzabal con Kreuzer Pacheco Hermanos ltda. con Ronald Chaytor y Cia. Ltda. (2011): Corte Suprema, 23 de junio de 2011 (incumplimiento contrato de transporte e indemnización por daño moral). Rol 7234-2009. Disponible en http://www.pjud.cl [fecha visita 11 de julio de 2016].

LANDEA, FRANCISCA CON ISAPRE CRUZ BLANCA S.A. (2015), Corte Suprema, 23 de diciembre de 2015 (incumplimiento contrato de Isapre). Rol 28857-2015. Disponible en http:// www.pjud.cl [fecha visita 20 de julio de 2016]. 
LazCANi con INmobiliaria Fourcade S.A. (2008), Corte Suprema, 29 de octubre de 2008 (incumplimiento contrato de construcción e indemnización por daño moral). Rol 4727-2007. Disponible en http://www.pjud.cl [fecha visita 10 de julio de 2016].

LEÓN CON HiNOSTROZA (2014): Corte Suprema, 8 de octubre de 2014 (incumplimiento de contrato de prestaciones médicas e indemnización por daño moral). Rol 21384-2014. Disponible en http://www.pjud.cl [fecha visita 12 de julio de 2016].

Lizana con Xinergia Laboral Servicios Generales Limitada (2011): Corte Suprema, 28 de septiembre de 2011 (incumplimiento contrato de construcción e indemnización por daño moral). Rol 9715-2010. Disponible en http://www.pjud.cl [fecha visita 8 de julio de 2016].

MERIŃo Con BANCo SANTANDER SANTiAGo (2010), Corte Suprema, 21 de octubre de 2010 (acción de responsabilidad contractual). Rol 1986-2009. Disponible en http://www. pjud.cl [fecha visita 12 de julio de 2016].

MoCKRIDGE CON YÁNEZ (2015): Corte Suprema, 15 de diciembre de 2015 (acción de responsabilidad contractual). Rol 16250-2015, acumulado rol 2284-2014.

montecinos con Hospital Clínico Pontificia Universidad Católica de Chile (2007): Corte Suprema, 25 de septiembre de 2007 (incumplimiento contrato de prestaciones médicas e indemnización por daño moral). Rol 4103-2005. Disponible en http://www. pjud.cl [fecha visita 8 de julio de 2016].

Mora con Isapre Colmena Golden Cross (2011): Corte Suprema, 25 de julio de 2011 (incumplimiento contrato de prestaciones médicas e indemnización por daño moral). Rol 3929-2010. Disponible en http://www.pjud.cl [fecha visita 8 de julio de 2016].

Morin con Chilquinta ENERGía S.A. (2010): Corte Suprema, 19 de octubre de 2010 (incumplimiento de contrato de servicios eléctricos e indemnización por daño moral). Rol 7076-2010. Disponible en http://www.pjud.cl [fecha visita 12 de julio de 2016].

NetZ CON THE WesSeX SCHOOL (2010), Corte Suprema, 7 de septiembre de 2010 (incumplimiento de contrato de prestaciones educacionales e indemnización por daño moral). Rol 1089-2009. Disponible en http://www.pjud.cl [fecha visita 12 de julio de 2016].

NúNez, María de los Ángeles con IGor Vladimir Tapia Torres (2010), Corte Suprema, 1 de marzo de 2010 (acción de responsabilidad contractual). Rol 6748-2009. Disponible en http://www.pjud.cl [fecha visita 12 de julio de 2016].

Nyborg, Alberto lustiano con Sepúlveda Sepúlveda, Fresia del Carmen (2011), Corte Suprema, 30 de diciembre de 2011 (contrato de promesa de compraventa, daño moral). Rol 165-2011. Disponible en http://www.pjud.cl [fecha visita 5 de julio de 2016].

OCARANZA CON ROBINSON (2006), Corte Suprema, 28 de noviembre de 2006 (contrato de prestaciones médicas). Rol 320-2005. Disponible en http://www.pjud.cl [fecha visita 12 de julio de 2016].

OChoran, Emilio con Gonzalez Rojo, Pablo (2014), Corte Suprema, 10 de noviembre de 2014, (incumplimiento de contrato de promesa y daño moral). Rol 474-2014. Disponible en http://www.pjud.cl [fecha visita 12 de julio de 2016].

OJEDA CON EDITORIAL JURÍDiCA CONOSUR (2008): Corte Suprema, 15 de enero de 2008 (incumplimiento contrato de edición e indemnización por daño moral). Rol 3070-2006. Disponible en http://www.pjud.cl [fecha visita 12 de julio de 2016]. 
Olguín con Sociedad de Inversiones Automotrices S.A. (2009): Corte Suprema, 5 de octubre de 2009 (incumplimiento contrato de compraventa e indemnización por daño moral). Rol 1922-2008. Disponible en http://www.pjud.cl [fecha visita 12 de julio de 2016].

Olivi, Germán con Banco Santander Chile (2011), Corte Suprema, 30 de marzo de 2012 (incumplimiento contrato de cuenta corriente e indemnización por daño moral). Rol 2560-2011. Disponible en http://www.pjud.cl [fecha visita 12 de julio de 2016].

OrozCo CON BANCO DE CHILE (2009): Corte Suprema, 7 de enero de 2009 (incumplimiento contrato de depósito e indemnización por daño moral). Rol 5814-2007. Disponible en http://www.pjud.cl [fecha visita 12 de julio de 2016]

Peralta con Hospital Clínico Universidad de Chile (2011), Corte Suprema, 12 de abril de 2011 (incumplimiento contrato de prestaciones médicas e indemnización por daño moral). Rol 6778-2008. Disponible en http://www.pjud.cl [fecha visita 12 de julio de 2016].

Pérez con BAnCo Citibank S.A. (2011), Corte Suprema, 11 de abril de 2011 (incumplimiento contrato de depósito e indemnización por daño moral). Rol 6937-2009. Disponible en http://www.pjud.cl [fecha visita 12 de julio de 2016].

Pesquera Luis Andrade S.A. con Marine Harvest Chile S.A. (2008): Corte Suprema, 30 de agosto de 2008 (incumplimiento contrato de arrendamiento e indemnización por daño moral). Rol 5857-2006. Disponible en http://www.pjud.cl [fecha visita 8 de julio de 2016].

PIDDO CON CABEZÓN (2011): Corte Suprema, 5 de octubre de 2011 (vicios redhibitorios e indemnización del daño moral). Rol 8441-2011. Disponible en http://www.pjud.cl [fecha visita 12 de julio de 2016].

Pinilla con Clínica Alemana de Temuco (2014): Corte Suprema, 12 de agosto de 2014 (incumplimiento contrato de prestaciones médicas e indemnización por daño moral). Rol 13845-2014. Disponible en http://www.pjud.cl [fecha visita 20 de julio de 2016].

Quiero con Sociedad de Turismo Concepción (2015): Corte Suprema, 12 de agosto de 2015 (incumplimiento de contrato de servicios de turismo). Rol 8340-2015. Disponible en http://www.pjud.cl [fecha visita 12 de julio de 2016].

Rafael Mouthon, María con Banco de Chile (1994): Corte Suprema, 20 de octubre de 1994 (incumplimiento contrato bancario y daño moral), RDJ, t. 91, secc. $1^{\text {a }}$, pp. 100105.

RAmírez y otro con Ruta de los Ríos Sociedad ConseCionaria S.A. (2011): Corte Suprema, 16 de diciembre de 2012 (incumplimiento contrato de servicios e indemnización por daño moral). Rol 2911-2011. Disponible en http://www.pjud.cl [fecha visita 12 de julio de 2016].

Ramírez, José Santiago con Klein Brintrup, Eduardo Augusto (2012), Corte Suprema, 26 de marzo de 2012 (incumplimiento contrato de compraventa e indemnización por daño moral). Rol 2632-2010. Disponible en http://www.pjud.cl [fecha visita 11 de julio de 2016]. 
Reyes, Patricio con Autofrance Ltda. (2012), Corte Suprema, 14 de agosto de 2012 (incumplimiento de contrato de compraventa e indemnización por daño moral). Rol 5447-2012. Disponible en http://www.pjud.cl [fecha visita 12 de julio de 2016].

Rochet con OKSEnberg y CLÍNica LAs Nieves S.A. (2008): Corte Suprema, 31 de marzo de 2008 (incumplimiento contrato de arrendamiento e indemnización por daño moral. Rol 4931-2006. Disponible en http://www.pjud.cl [fecha visita 12 de julio de 2016].

Rojas, YAsna con Fisco de Chile y otro (2012), Corte Suprema, 30 de octubre de 2012 (responsabilidad médica contractual y daño moral). Rol 4404-2012. Disponible en http://www.pjud.cl [fecha visita 7 de julio de 2016].

Ruiz con Instituto de Diagnóstico S.A. (2011): Corte Suprema, 25 de mayo de 2011 (incumplimiento contrato de servicios e indemnización por daño moral). Rol 70082009. Disponible en http://www.pjud.cl [fecha visita 9 de julio de 2016].

Sandoval VÁsquez Jorge Andrés con Distribuidora de Industrias Nacionales S.A. (2013), Corte de Apelaciones de Concepción, 24 de junio de 2013 (indemnización de perjuicios, ley 19.496). Disponible en http://www.pjud.cl [fecha visita 4 de julio de 2016].

Silva, Juan Matias con Central Parking System Chile S.A. (2015), Corte de Apelaciones de Santiago, 19 de febrero de 2015 (incumplimiento contrato de estacionamiento e indemnización por daño moral). Rol 1691-2014. Disponible en http://www.pjud.cl [fecha visita 8 de julio de 2016].

Silva con Vorbeza Corredores de Seguros Ltdda. (2010), Corte Suprema, 10 de noviembre de 2010 (incumplimiento contrato de seguros e indemnización por daño moral). Rol 7749-2010. Disponible en http://www.pjud.cl [fecha visita 8 de julio de 2016].

Sociedad INMOBILIARIa TALASIA LTDA. (2008) Corte Suprema, 27 de marzo de 2008 (vicios redhibitorios e indemnización por daño moral). Rol 6700-2006. Disponible en http:// www.pjud.cl [fecha visita 12 de julio de 2016].

Stange, Eduardo con Ripley Puerto Montt (2012), Corte Suprema, 2 de octubre de 2012 (incumplimiento de contrato de tarjeta de crédito e indemnización por daño moral). Rol 8607-2012. Disponible en http://www.pjud.cl [fecha visita 9 de julio de 2016].

Toro, Claudia con Concha Sandoval, ÁnGel (2012), Corte Suprema, 13 de junio de 2012 (incumplimiento contrato de práctica educacional e indemnización por daño moral). Rol 2220-2011. Disponible en http://www.pjud.cl [fecha visita 12 de julio de 2016].

TRoncoso con Banco SANTiago (2006): Corte Suprema, 20 de diciembre de 2006 (incumplimiento contrato de tarjeta de crédito e indemnización por daño moral). Rol 18522006. Disponible en http://www.pjud.cl [fecha visita 8 de julio de 2016].

TRUjillo con Mundi Y OtRos (2015): Corte Suprema, 26 de octubre de 2015 (acción de responsabilidad contractual). Rol 24995-2014. Disponible en http://www.pjud.cl [fecha visita 12 de julio de 2016].

Valenzuela y otros con Inmobiliaria Petrohue S.A. y otra (2011): Corte Suprema, 28 de septiembre de 2011 (incumplimiento contrato de construcción e indemnización por daño moral). Rol 1474-2010. Disponible en http://www.pjud.cl [fecha visita 12 de julio de 2016]. 
Venegas Castro Jaime Guillermo con Inmobiliaria Río Trancura (2009): Corte Suprema, 3 de noviembre de 2009 (incumplimiento contrato de promesa e indemnización por daño moral). Rol 7957-2009). Disponible en http://www.pjud.cl [fecha visita 7 de julio de 2016].

Vergara, Rodrigo con Latam Airlines Group S.A. (2015), Corte de Apelaciones de Santiago, 27 de febrero de 2015, (incumplimiento contrato de transporte e indemnización de daño moral). Rol 1603-2014. Disponible en http://www.pjud.cl [fecha visita 8 de julio de 2016].

Zapata, María Isabel con Bahamonde Lazo Gustavo (2012), Corte Suprema, 4 de mayo de 2012 (incumplimiento contrato de construcción e indemnización del daño moral). Rol 165-2010. Disponible en http://www.pjud.cl [fecha visita 12 de julio de 2016].

ZEPEDA CON EMPRESA DE OBRAS y Montajes OVALLE (2009): Corte Suprema, 26 de enero de 2009 (incumplimiento contrato de construcción e indemnización por daño moral). Rol 5329-2007. Disponible en http://www.pjud.cl [fecha visita 12 de julio de 2016]. 